\title{
Bastint l'antifranquisme de masses. La JCC més enllà de la Gran Barcelona, 1962-1976
}

\author{
CRISTIAN FERRER GONZÁLEZ \\ Centre d'Estudis sobre les Ėpoques Franquista i Democràtica \\ de la Universitat Autònoma de Barcelona (Espanya) \\ orcid.org/0000-0001-7215-2239
}

Presentació: 1 oct. 2016 | Acceptació: 7 nov. 2016 | Publicació: 15 des. 2016

Citació recomanada: FerRer GonzÁLez, Cristian. «Bastint l’antifranquisme de masses. La JCC més enllà de la Gran Barcelona, 1962-1976». Franquisme \& Transició. Revista d'Història i de Cultura 4 (2016): 153-199. doi: http://dx.doi.org/10.7238/fit.voi4.3055

Resum: La irrupció d'una mobilització obrera i estudiantil de nou tipus en els anys cinquanta va imposar un canvi en l'estratègia de lluita dels comunistes envers el franquisme. El treball entre les masses va anar guanyant complexitat i, juntament amb l'obrer, el front estudiantil va cobrar protagonisme. Al llarg dels anys seixanta, el Partit Comunista d'Espanya (PCE) i el Partit Socialista Unificat de Catalunya (PSUC) van realitzar un esforç organitzatiu -i no solament propagandístic - per tal d'ampliar llur influència cap aquests i altres sectors: als previs, s'hi sumaren el de comarques, el camperol o el de dones. Entre aquests, un dels que centraria els seus esforços va ser el treball entre el jovent a través de sengles organitzacions juvenils: la Unió de Joventuts Comunistes d'Espanya (UJCE) i, en terra catalana, la Joventut Comunista de Catalunya (JCC). Aquest article ressegueix el desenvolupament del moviment juvenil que els comunistes van impulsar i liderar a Tarragona des de l'inici de la dècada dels anys seixanta fins a la seva sortida a la superfície, el 1976.

Paraules clau: antifranquisme, comunisme, moviments socials, moviment juvenil, moviment obrer, moviment estudiantil, moviment pagès, organitzacions juvenils, industrialització

Nota: Aquesta recerca forma part del projecte HAR2015-63657-P, finançat pel Ministeri d'Economia i Competitivitat espanyol i pel Fons Europeu de Desenvolupament Regional de la Unió Europea, i s'inscriu en la meva investigació doctoral sobre l'antifranquisme a comarques.

FRANQUISME \& TRANSICIÓ 4 (2016) ISSN 2014-511X PUNCTUM, UNIVERSITAT OBERTA DE CATALUNYA \& FUNDACIÓ CARLES PII SUNYER 


\section{Building a mass anti-Francoism: The JCC beyond Greater Barcelona (1962-1976)}

Abstract: When labour and student movements of a new kind emerged in the 1950s, Communists had to change their strategy for fighting the Franco dictatorship. Working with the masses began to become more complex, and student organizations took prominence besides those of workers. During the 196os, the Spanish Communist Party (PCE, in its initials in Catalan) and the Unified Socialist Party of Catalonia (PSUC) made efforts to increase their influence beyond Greater Barcelona. These efforts included sectors such as farmworkers and women, and the Communists also focused on young people as a strategic mobilization front. They did so through the Communist Youth Union of Spain (UJCE) and, in Catalonia, the Catalan Communist Youth (JCC). This paper follows the development of the youth movement that was driven and led by the Communists in Tarragona between the early 1960s and the JCC's egress in 1976. Keywords: Anti-Francoism, Communism, social movements, youth movements, labour movements, student movements, farmworkers' movements, youth organizations, industrialization

\section{La historiografia sobre la Joventut Comunista}

Salta a la vista que les organitzacions comunistes juvenils no han centrat l'atenció preferent de la investigació. Si bé disposem d'estudis des d'òptiques diverses i de gran interès sobre les Joventuts Socialistes Unificades (JSU), ${ }^{1}$ a hores d'ara només podem donar compte d'una sola monografia que hagi centrat l'anàlisi en la Joventut Comunista durant la dictadura franquista. ${ }^{2}$ En aquest sentit, el present article ni podria ni pretén ser una història sistematitzada de la JCC. En gran part l'esforç seria en va, perquè ja en disposem d'una excellent monografia. ${ }^{3}$ La seva ambició és més modesta. Es tracta d'assenyalar el paper fonamental que va tenir la JCC en un microcosmos particular fora de l'àrea industrial de la Gran

1 ViÑaS 1978; FernándeZ Soria 1992; CaSAdo GómeZ 2007. Recentment s'ha publicat una panoràmica de l'etapa republicana des de l'òptica de les organitzacions juvenils d'esquerres, Souto KUSTRÍN 2016.

2 Domènech 2008. Hi ha referències parcials sobre la JCC a ACili, Mayayo \& Segura 2003; Herbera 2006; HeRAS 1991.

3 Domènech 2008. 
Barcelona: ${ }^{4}$ la ciutat de Tarragona i el seu hinterland. No obstant això, no he declinat d'incloure-la dins el marc polític general.

Les fonts primàries emprades aquí són certament fragmentades. Tot $\mathrm{i}$ haver consultat les sèries documentals completes de la JCC dipositades en el fons del PSUC de l'Arxiu Nacional de Catalunya i el fons d'Organizaciones Juveniles a l'Archivo Histórico del PCE, he hagut de recórrer a d'altres per tal de reconstruir el procés de formació i desenvolupament de la JCC i del moviment juvenil antifranquista que aquesta organització va impulsar. Això és, la documentació del PSUC disponible en arxiu del PCE ja esmentat, especialment els informes d'organització a comarques i la correspondència entre els comitès de base i els seus òrgans dirigents. A l'Archivo Histórico del Trabajo (Fundación $1^{\circ}$ de Mayo) he llegit butlletins clandestins de la JCC, alguns dels quals eren de molt curta vida i de difícil localització; un cert nombre d'aquests documents, si bé no tots, també estan disponibles en el fons hemerogràfic del PCE, a través de la Biblioteca Virtual de Premsa Històrica del Ministeri d'Educació i Cultura, i en l'Arxiu Històric de la Comissió Obrera Nacional de Catalunya (Fundació Cipriano Garcia), que també han estat objecte de consulta per a aquesta investigació. El fons d'Iniciativa per Catalunya Verds tarragonina, dipositat a l'Arxiu Històric de la Ciutat de Tarragona, custodia fonts sobre el PSUC i la JCC de la dècada dels setanta, tant de la ciutat com de l'organització intercomarcal, que fins ara havien romàs inèdits.

Amb tot, aquest escrit no esgota els camps d'anàlisi oberts en el text $\mathrm{i}$ ha de ser vist com una aproximació fragmentada i incompleta a un front de treball estratègic del PSUC a partir del cas tarragoní. La pretensió d'aquestes línies no és altra que, en definitiva, contribuir a conèixer millor el quefer de l'antifranquisme fora dels escenaris principals de conflictivitat social i política del país prenent com a base una experiència concreta: una aproximació microhistòrica a una temàtica, la de la joventut durant el franquisme tardà, que ha estat definida en si mateixa com a microhistòria. ${ }^{5}$ Sens dubte, tal aproximació a l'objecte d'anàlisi ens aju-

4 En el text utilitzo el terme Gran Barcelona per referir-me al conglomerat metropolità que tenia en un radi d'uns 50 quilòmetres la ciutat de Barcelona com a centre neuràlgic. Prenc el terme encunyat en l'estudi clàssic de BALFour 1994, 59 i s.

5 Acili, Mayayo \& Segura 2003, 27.

FRANQUISME \& TRANSICIÓ 4 (2016) ISSN 2014-511X PUNCTUM, UNIVERSITAT OBERTA DE CATALUNYA \& FUNDACIÓ CARLES PI I SUNYER 
darà a comprendre'n la complexitat i ens permetrà, parafrasejant Natalie Zemon Davis, furgar amb la nostra ploma les petites interaccions, sovint invisibles, des d'una altura superior.

\section{La ciutat, el canvi econòmic i el canvi social}

Promogut per l'Institut Nacional d'Indústria, Tarragona va experimentar al llarg dels anys seixanta un procés d'industrialització accelerat, especialment intens en el sector petroquímic. ${ }^{6}$ Si bé Reus gaudia d'una llarga tradició tèxtil i el Camp de Tarragona, en conjunt, d'una tradició de producció vitivinícola, la ciutat de Tarragona no disposava de cap indústria capdavantera abans del 1955 i el seu teixit industrial es fonamentava en petites empreses del subsector químic, del tèxtil i de l'alimentació, la majoria de les quals eren de capital estranger. L'entrada fluida de divises després de la implementació del Pla d'Estabilització del 1959 va afavorir la industrialització intensiva de la zona. Sens dubte, les facilitats fiscals i la política pública de construcció de macropolígons van contribuir-hi decisivament i per als inversos aquella va ser una operació altament rendible.

D'altra banda, la demanda de mà d'obra va atreure enormes contingents humans des de les zones limítrofes i, sobretot, des d'altres regions. Entre el 1955 i el 1975, la població de Tarragona va créixer un $157 \%$. El 1970, un de cada dos joves de quinze a vint-i-quatre anys i el 62,6\% dels adults de fins a quaranta-quatre anys residents a Tarragona, havien nascut en altres províncies, majoritàriament de fora de Catalunya. Amb tot, l'absorció poblacional de què van ser objecte els municipis veïns no va afectar-ne el sector primigeni. Ans al contrari. Després d'un procés de mecanització i d'expansió de les zones de regadiu, la producció agrícola va augmentar, si bé la seva valoració en el mercat va tendir a la baixa. Així, doncs, les noves empreses petroquímiques i de productes associades van conviure amb la tradicional indústria tèxtil i agroalimentària. La ciutat gaudia, a més a

6 Es pot resseguir el procés d'industrialització mitjançant les «Memorias de Gestión de Gobiernos Civiles», Tarragona, corresponents als anys 1960, 1962, 1963, 1965, 1966 i 1968, que són disponibles a l'Archivo General de la Administración (AGA), al fons de Gobernación, caixes 44/11314, 44/11331, 44/11463, 44/11696, 44/12141 i 52/o0487, com també amb la bibliografia sobre la temàtica: Margalef 1979; Llop Tous 2002, 33-130; Molinero 1997, 298-301. 
més, d'un important sector de la construcció que derivava del mateix bastiment d'enclavaments industrials, en gran manera nodrits per treballadors precaris procedents de la immigració des del mezzogiorno espanyol.

Així les coses, en els anys setanta Tarragona s'havia convertit en una moderna metròpolis, en la segona àrea industrial de Catalunya. La industrialització va canviar la fisonomia de la ciutat i va transformar-ne el teixit social. L'altra cara de l'enriquiment dels industrials, però, va ser el canvi dràstic de vida que la industrialització va comportar. Rafael Fernández Martínez, governador civil de la província, en un informe elaborat en ple procés d'industrialització, relatava: «Subsisten los mismos problemas sociales [...] muy poco se ha avanzado en lo que respecta a la situación de la vivienda, prosiguiendo la anarquía de construcción de barracones y chabolas [... que] han adquirido extraordinario desarrollo, de manera especial en Reus y Tarragona».?

Aquest era el context material en què vivien milers de persones. No es tracta d'assumir-lo com a motiu determinant d'una actuació sociopolítica concreta, sinó d'assenyalar les condicions en les quals les organitzacions antifranquistes van desenvolupar la seva acció d'agitació, de mobilització, d’organització; en suma, de lluita contra el franquisme. Sovint ho feien en contra d'aquestes condicions, i, en aquest procés dialèctic, van convertir-se en quelcom diferent del que havien estat. La forja de fortes identitats de classe, de barri o de poble impulsava la mobilització social, que, al mateix temps, transformava el marc en què es veien obligats a moure's i reforçava les identitats de grup.

En aquest sentit resulta d'interès portar a collació el cas de la JCC a Tarragona, perquè va ser la principal organització juvenil de masses de l'antifranquisme. Ho va ser en uns temps particulars, el franquisme. Però també en un període de profunds canvis que van alterar intensament les relacions econòmiques, demogràfiques, ecològiques i socials del territori i entre els seus individus. El jovent no va ser aliè a aquestes transformacions, i el seu quefer quotidià va estar molt determinat per

7 «Programa de actuación trimestral», remès a la Secretaría General Regional de la Jefatura Superior de Policía de Barcelona, juny de 1964, Fons del Govern Civil, caixa (c.) 4367, Arxiu Històric Provincial de Tarragona (AHPT). 
aquest context. Fossin les condicions laborals, la massificació o la seva deficiència formativa en els centres d'educació secundària, fos la manca d'equipaments municipals i d'activitats lúdiques i recreatives per poder desenvolupar-se com a joves, en el fons es trobava un sistema polític que reglamentava severament les seves vides. Per això molts joves van decidir engrandir una organització per enfrontar-se al franquisme. Aquesta, però, no va ser mai l'opció natural de cap sector o classe determinada per la seva experiència objectiva, sinó que tenia a veure amb les mateixes expectatives, amb contextos d'amistat i de treball, àdhuc amb les tradicions familiars que s'havien mantingut a pesar de la dictadura. És a dir, malgrat el seu context. Un context, en definitiva, que la mateixa acció de l'antifranquisme va anar modificant i unes expectatives individuals que estaven mediatitzades per les trinxeres contrahegemòniques que els moviments d'oposició van anar conquerint durant aquells anys.

\section{Vers la reconstrucció de l’espai juvenil (1962-1970)}

La reconstrucció de les joventuts comunistes es va iniciar a la primeria dels anys seixanta. ${ }^{8}$ Les JSU havien estat abandonades al començament de la dècada anterior amb la finalitat d'enfortir el partit — gairebé es podria dir que havien caigut en desús. La renovada UJCE, que recuperava la històrica denominació de les joventuts del PCE, era el producte derivat del canvi estratègic adoptat pels comunistes. Aquests havien iniciat un gran període transitori després de la vaga general del març del 1951 a Barcelona i del fracàs del jornadisme de 1956-1958, un període en què, tot i això, les oscillacions en la línia estratègica van ser permanents. Un període que pot donar-se per conclòs després de les vagues d'Astúries de la primavera del 1962, quan el PCE i el PSUC van fixar definitivament la política d'actuació en el moviment obrer a través de l'instrument sorgit de la mateixa acció vaguística, les Comissions Obreres (CCOO). ${ }^{9}$

8 En el text utilitzaré «JC» per referir-me a les organitzacions locals del jovent comunista prèvies al $1970 \mathrm{i}$ «JCC» quan aquestes van coordinar-se en l'àmbit nacional i van dotar-se d'una estructura orgànica específica.

9 La majoria d'estudis hi coincideixen. Sense voluntat de ser exhaustiu, cfr. BALFOUR 1994, 8081; BABIANO 1995, 233 i s.; Molinero \& YsÀs 1998, 141, 154 i 262-263; Molinero \& Ysàs 2010, 30-31; 
Després del III Ple del Comitè Central, celebrat l'octubre del 1961, el PCE va aprovar la reconstrucció de la UJCE. «Todo el mundo reconoce el papel jugado por la juventud en los últimos acontecimientos [vaguístics del 1962]», s'afirmava en una carta enviada el juliol a totes les organitzacions del partit i per la qual s'instaven tots els comitès i les cèllules a impulsar espais d'organització autònoma per al jovent comunista, amb la finalitat de potenciar l'antifranquisme com a moviment social i no exclusivament polític. ${ }^{10}$ L'estratègia dels comunistes per fomentar el treball en el moviment obrer a través de CCOO va tenir el seu propi correlat juvenil amb l'impuls de les Comissions Obreres Juvenils (COJ). En aquesta primera etapa de desenvolupament de les JC, les COJ van ser la base des de la qual creixeria el nou moviment juvenil, especialment a partir de la dècada següent. Les primeres COJ van aparèixer el 1967, i al llarg de l'any següent s'havien estès per les barriades de les principals ciutats catalanes: des de Barcelona, Badalona, Sabadell o Terrassa, van proliferar molt més enllà del segon cinturó metropolità. ${ }^{11} \mathrm{~A}$ inicis del 1968 ja existien grups de la COJ a Reus i a les barriades tarragonines de Torreforta i Bonavista, tot i que va ser el 1969 quan sortiren a la llum pública durant les accions del Primer de Maig. ${ }^{12}$

No obstant això, fins al 1969 la JC era una realitat fonamentalment circumscrita a la Gran Barcelona. Certament n'hi havia ja alguns nuclis incipients a Lleida, Tarragona i Reus, però la seva dependència dels comitès locals del PSUC i el treball que duia a terme (més d'agitació i propaganda que d'acció sociopolítica) fa que difícilment puguem comparar-ne el grau de desenvolupament respecte al d'organitzacions com les de Badalona, Sabadell i, sobretot, Terrassa. A la Gran Barcelona, la JC havia estat actuant principalment en dos fronts: les COJ i les anomenades Comis-

\footnotetext{
Treglia 2012, 123; DOMÈneCH 2008, 46.

10 «Carta a todos los comités del Partido sobre las medidas para acelerar la reconstrucción de la Unión de Junventudes Comunistas de España», 25 jul. 1962, Fons Ministerio de Información y Turismo (MIT), Gabinete de Enlace (GE), Comunismo, c. 42/9099, carpeta (cp.) 8, AGA.

11 «A los jóvenes trabajadores ante las jornadas del 30 de abril y $1^{\circ}$ de mayo», 16 abril 1968, Fons PSUC, unitat de catalogació (uc.) 1544, c. 127, Arxiu Nacional de Catalunya (ANC).

12 Josep PARDELL, «Carta de Sitges», 26 març 1968, Fons Nacionalidades y Regiones (NyR), Catalunya, jaquets (jj.) 1873-1874, Archivo Histórico del Partido Comunista de España (AHPCE); HERAS 1991, 32.
} 
sions d'Estudiants de Batxillerat (CEB). L'organització dels batxillers en comissions no va arribar a produir-se a Tarragona fins al 1972. Precisament a través d'aquests sectors, a inicis dels anys setanta la JC tarragonina va incrementar els seus contingents i va poder anar més enllà de la base tradicional dels comunistes.

Allí on n'hi havia, les estructures orgàniques entre aquestes CEB i les JC sovint eren indistingibles. Això els va comportar grans costos repressius durant l'estat d'excepció del $1969 \cdot{ }^{13}$ Aquest fet va accelerar el procés de coordinació nacional de les JC disperses arreu del territori. Barcelona, Terrassa, Sabadell, Badalona, Baix Llobregat, Blanes, Manresa, Lleida, Baix Ebre i Reus eren les agrupacions participants en la reunió constituent de la JCC, segons les actes de la trobada. ${ }^{14}$ Presidida per un retrat de Dolores Ibárruri, la reunió constituent de la JCC es va celebrar a Barberà del Vallès i va gaudir de la presència del secretari d'organització del PSUC, Josep Román Serradell. D’aquelles JC que van concertar la cita, només la de Mataró no va poder assistir-hi finalment, però se'ls reservà un lloc en l'executiva. A pesar d'existir-hi un petit grup organitzat, la JC de Tarragona no va ser present a la reunió constituent «por tener efectivos reducidísimos [...] y dificultades de organización». ${ }^{15}$ En efecte, en l'etapa iniciàtica, la JC tarragonina va estar intensament vinculada a la de Reus i, sobretot, a Josep Colomé, que en fou el responsable polític i membre del Comitè Executiu nacional. Sovint, la documentació referencia l'organització tarragonina com a «Reus-Tarragona», ja que, en la pràctica, Reus devia assistir a l'assemblea constituent de la JCC en representació de les comarques del Camp de Tarragona en conjunt, tal com Tortosa hi va anar en representació de les comarques del Baix Ebre i del Montsià.

A Tarragona, fins als primers anys setanta, la JC va tenir una activitat escassa i sempre va estar supeditada al PSUC. El comitè local del partit semblava que no entenia les necessitats de mantenir dues estructures orgàniques paralleles i els joves que hi ingressaven a través de la JC eren transferits al PSUC al cap de poc temps. En un informe sobre la si-

13 Miguel NúÑ̃z, «Carta de Saltor», 8 març 1969, NyR, Catalunya, jaquet (j.) 1899, AHPCE.

14 «Acta de la reunión constituyente de la Juventud Comunista de Cataluña», juny 1970 [30 maig 1970], Fons Organizaciones Juveniles (OOJJ), JCC, c. 153, AHPCE.

15 Josep SerradelL, «Carta de Miró», 6 juny 1970, NyR, Catalunya, c. 59, cp. 1, AHPCE. 
tuació del partit a comarques es podia llegir aquesta informació sobre Tarragona:

Queda por realizar la formación de una dirección amplia de la juventud y el que los camaradas de la dirección local del Pdo. dejen «volar por sus propias alas» a estos camaradas jóvenes, entre cuyos dirigentes hay chicos estupendos. Es natural que los camaradas del Pdo. les ayuden tal como hasta ahora han venido haciendo, pero no deben perpetuar el método de asistir a todas y cada una de las reuniones que llevan a cabo los camaradas jóvenes. ${ }^{16}$

El primer espai pròpiament juvenil en el qual van actuar els comunistes a Tarragona va ser el Club de Joves. Constituït el 1965 sota l'empara de l'Arquebisbat, el club tenia diverses seccions (excursionista, teatral, musical, esportiva), s'hi realitzaven sessions de cinefòrum i conferències i, durant un temps, va ser l'única entitat que oferia classes de català. Els seus locals estaven situats a la part alta de la ciutat i van esdevenir un espai de trobada del jovent tarragoní ideològicament plural: hi convivien catalanistes, cristians, trotskistes i comunistes sota l'hegemonia inicial de la Joventut Obrera Catòlica (JOC) ${ }^{17}$ El curt període d'esplendor del Club de Joves es va circumscriure a 1968-1969, anys en els quals els mesos de juliol es van celebrar les setmanes del club farcides d'activitats culturals alternatives. ${ }^{18}$ La crisi oberta al Club els anys següents va impedir que les activitats d'aquesta magnitud se seguissin portant a cap amb la mateixa intensitat dels temps precedents - tot i el concert de Lluís Llach que va organitzar al Camp de Mart el 1970. ${ }^{19}$ Ja no li bastava amb les pròpies forces, per la qual cosa amb l'arribada de la nova dècada el Club de Joves va haver de disposar permanentment de la cooperació de la Llibreria de la Rambla, un dels centres neuràlgics de l'antifranquisme tarragoní. ${ }^{20}$

16 Josep SerradelL, «Carta de Miró», 4 juny 1969, NyR, Catalunya, jj. 1912-1913, AHPCE.

17 Josep SerradelL, «Carta de Miró», 3 juliol 1969, NyR, Catalunya, c. 58, cp. 5, AHPCE.

18 Rovira i Gómez 2010, 68-72.

19 Súplica del president del Club de Joves, Ernest Gatell, al governador civil de Tarragona, 2 setembre 1970, GC, c. 1329, AHPT.

20 MarRugat 2012, 148. 
Amb tot, aquest club pertanyia a un món completament diferent del de la majoria dels futurs militants comunistes joves. En aquest sentit, la primera JC tarragonina va néixer amb un problema d'extracció social que en limitava les capacitats d'incidència. Així ho recorda la jove comunista de la barriada tarragonina de Bonavista Carmen Almonacid:

Los jóvenes en Bonavista solían empezar a trabajar muy pronto (16/18 años) y de militar en alguna parte preferían hacerlo directamente en el PSUC y CCOO, donde lo hacían sus propios compañeros de trabajo, sintiéndose por ello más cómodos. También es cierto que a la hora de relacionarse siempre existió una cierta falta de sintonía entre los jóvenes comunistas de los barrios como Bonavista o Torreforta, con los que lo hacían en el centro de la ciudad, pues en general tenían orígenes, niveles culturales, formas de vida, gustos y problemáticas bastante diferentes. Por otro lado, otro factor a tener en cuenta era el de la lengua: a la hora de expresarse, los de los barrios eran en su mayoría castellanoparlantes y los del centro de la ciudad, catalanoparlantes. ${ }^{21}$

I és que, de fet, en els espais vivencials les COJ i les JC havien aconseguit articular amb més èxit un moviment ampli de joves en demanda de tipus estructural i en les organitzacions de barri a la Gran Barcelona. ${ }^{22}$ A Tarragona, però, això encara no havia succeït. La debilitat del PSUC fins ben entrats els anys seixanta no feia viable desviar recursos cap a altres estructures organitzatives $i$, en tot cas, el jovent obrer participant de l'incipient moviment veïnal — en virtut de joves del barri- a Bonavista, Torreforta i la Floresta optaven per fer-ho encara a través del PSUC — un partit certament jove pel que fa a la composició-, en lloc de dur-ho a terme en unes JC recloses al centre de la ciutat i mancades d'autonomia orgànica real..$^{23}$

21 Entrevista a Carmen Almonacid, recollida a BARDAJí 2015, 136.

22 «Reflexiones sobre organización», abril de 1969, NyR, Catalunya, c. 52, cp. 3, AHPCE.

23 En un informe del 1973, Roure mencionava que la composició idiomàtica dels militants tarragonins era en un $80 \%$ de parla castellana. A més, en destacava que Torreforta i Bonavista actuessin, en la pràctica, com a organitzacions locals independents de Tarragona. Cfr. Josep PARDELL, «Algunes informacions de les Organitzacions del Partit a Comarques», abril de 1973, NyR, Catalunya, c. 63, cp. 1/1, AHPCE. Un altre fet rellevant sobre la composició idiomàtica és la distribució de premsa 
En efecte, l'empremta que deixaven les $\mathrm{CCOO}$ en tota l'extensió territorial era recorreguda pels joves obrers a les barriades i aquests, d'un mode natural, tendien a agrupar-se entorn d'altres joves com ells. Ho feien en parròquies, clubs de futbol o altres espais juvenils dels barris, i no tant a la ciutat. Abans del 1970 a aquests grups se'ls va anomenar COJ. Tot i això, la dinàmica que va adquirir la JCC els anys següents va deixar caduques les COJ i, a excepció de casos amb una alta capacitat de mobilització i diversificació d'actuacions, com ara Terrassa, aquestes van tendir a desaparèixer els anys setanta. La direcció del PSUC lamentava que «les COJ s'han transformat en llocs d'enfrontament [...] mancades dels joves treballadors de les grans empreses», fet que les reduïa a «clubs de discussió ideològica». ${ }^{24}$ Durant els anys setanta, el jovent obrer va participar directament a CCOO, ja que la seva actuació peremptòria per reforçar el moviment obrer no necessitava cap estructura orgànica pròpia, sinó un teixit social juvenil, al qual la JCC va contribuir tot ampliant els límits del moviment. En l'entorn juvenil no era tan central la fàbrica com ho era el barri, i a través de l'eixamplament d'altres moviments, com ara l'estudiantil o el pagès, el límit s'ampliava fins a la ciutat i la comarca.

El salt qualitatiu definitiu per a l'antifranquisme a comarques es va produir arran del procés de Burgos, celebrat el desembre de 1970. A Tarragona, CCOO va cridar a manifestar-se per l'amnistia el 3 de novembre, il'1 de desembre es va produir un intent d'ocupar-ne la catedral. ${ }^{25} \mathrm{~A}$ Reus, la trobada de pocs centenars d'antifranquistes a la plaça de Prim va contribuir a recuperar la vida política de l'organització comunista. La concentració havia estat impulsada per l'Aliança Democràtica de Reus, una plataforma que aglutinava comunistes, socialistes, democratacristians i republicans. A inicis de la nova dècada, però, tant el partit com les recents formalitzades JCC van ser objecte de la repressió dictatorial. Primer ho fou el PSUC,

clandestina, en què la relació entre Mundo Obrero i Treball era de noranta per quaranta. Cfr. «Distribución propaganda comarcas catalanes», març de 1972, PSUC, uc. 607, c. 25, ANC.

24 Gregori López RAImUNDo, «Fem convergir en un sol torrent les forces que s'oposen a la dictadura», V Reunió Plenària del CC del PSUC, setembre de 1970, PSUC, uc. 47, c. 4, ANC.

25 Full volant de CCOO de Tarragona i província contra el judici de Burgos, 3 novembre 1970, PSUC, uc. 1603, c. 130, ANC. En bolígraf hi ha anotat «Octavillas, de esta 6.00o. Estas fueron tiradas el mismo día 3 de Nov.». 
l'agost del 1970, els membres més actius del qual van ser detinguts i durament torturats per la policia. ${ }^{26} \mathrm{Un}$ any després, el juliol i setembre del 1971, van caure diversos militants juvenils de Reus i Tarragona. ${ }^{27}$ La crisi que aquesta caiguda va obrir dins l'organització, conceptualitzada per la direcció del PSUC d'òptima, ${ }^{28}$ es va accentuar amb la partença de Josep Colomé a realitzar el servei militar al final del $1972 .{ }^{29}$ La JCC va quedar com un grup formalment constituït, però sense activitat i vida política regular. La situació d'atonia es va allargar fins que va sorgir un nou espai que va permetre enfortir l'organització: el moviment de batxillers.

\section{El conflicte dels batxillers i l’ampliació del moviment (1972-1974)}

Les protestes contra la Llei general d'educació (LGE) del ministre Villar Palasí van revitalitzar el moviment estudiantil, després d'anys d'estancament. En el període d'aplicació de la llei ja va generar neguit entre els estudiants i el professorat, sobretot per la introducció de la selectivitat. A més de les universitats, el descontentament s'estenia, per primer cop, als centres d'educació secundària i professional. Era una mostra patent de l'hegemonia de l'oposició entre grans segments de la societat i del fet que la socialització antifranquista s'iniciava a una edat primerenca. Les protestes del 1972 van ser molt àmplies. Fins i tot les Comissions de Pagesos i Jornalers del Camp Català (CCPP n'és la sigla més habitual) van donar cabuda a les demandes dels estudiants en la seva premsa. Ho van fer per mitjà de les reivindicacions dels pagesos com a estudiants de peritatge agrícola i tècnics agraris. En alguns casos, diversos pagesos van acudir a les manifestacions amb els seus fills. ${ }^{30}$

El 14 de febrer de 1972, el ministre d'Educació Villar Palasí havia de comparèixer a les Corts per valorar l'aplicació de la LGE. El moviment es-

26 «Informe (Tarragona)», setembre de 1970, NyR, Catalunya, c. 63, cp. 16, AHPCE.

27 El febrer de 1971 va ser detinguda la responsable local del PSUC a Reus, Isabel Llacer, poc després que també fossin arrestats militants del MSC i del PSOE de la ciutat.

28 Josep Pardell, «Carta de Serós. D’algunes Organitzacions del P. a Comarques», 2 abril 1971, NyR, Catalunya, c. 59, cp. 3, AHPCE.

29 Heras 1991, 59.

30 «El conflicte dels estudiants de l'Escola de Pèrits Agrícoles», La Veu del Camp Català 33 ([gen.febr.] 1972), suplement. 
tudiantil, que recentment s'havia articulat en l'àmbit estatal, va convocar una jornada de vaga general aquell mateix dia amb la voluntat manifesta de desafiar el ministre. Tot i la precipitació de la convocatòria i l'escassa representativitat dels delegats que assistiren a la I Reunió General d'Universitats a Madrid, des de la qual es va cridar a la vaga general, la jornada del 14 de febrer va tenir un acolliment inèdit. ${ }^{31}$

Tots els contactes previs que s'havien fet durant el curs 1971-1972 van florir en el període preparatori de la vaga general..$^{32} \mathrm{~A}$ Tarragona van secundar-la els últims cursos de l'institut de segona ensenyança de COU, com també els de formació professional. A l'Escola Normal de Magisteri el seguiment va ser desigual per cursos, mentre que a la Facultat de Lletres i Ciències de la delegació universitària ubicada a la plaça de la Imperial Tàrraco va ser pràcticament total. Tres dies abans, els estudiants ho havien decidit en una assemblea celebrada de forma oberta i el dia 14 estaven disposats a donar visibilitat a la seva protesta amb una manifestació per la Rambla Nova. Però la permanent presència de la policia armada no ho va fer possible. Diferent era la situació a la Universidad Laboral Francisco Franco, on inicialment no es va secundar la vaga. Tan sols el jove comunista Enrique Gómez León ${ }^{33}$ estava disposat a fer-la, ja que es va dedicar a recórrer totes les classes donant a conèixer als seus companys el que estava succeint a la ciutat. Els exhortava a reunir-se amb ell a la cafeteria per explicar-los-en més coses, una cita a la qual van acudir, segons aquesta font, tres-cents alumnes. ${ }^{34}$ Tot assumint un cert optimisme en les dades aportades pels informes del PSUC, el seguiment global de la jornada pot qualificar-se d'elevat per a una ciutat com Tarragona: gairebé dos mil estudiants van secundar la vaga contra la LGE. ${ }^{35}$

31 Colomer 1978, 8o-81.

32 Miguel NúñEz, «Carta de Saltor», 5 febrer 1972 i 7 febrer. 1972, NyR, Catalunya, c. 59, cp. 5, AHPCE.

33 Segons les diverses fonts consultades, la JCC disposava únicament d'un militant a la Universidad Laboral de Tarragona (probablement fos Enrique Gómez León). Entrevista a Josep Sánchez Cervelló, 20 juny 2016.

34 La xifra és, amb tota seguretat, exagerada, ja que el 1971 la Universidad Laboral de Tarragona tenia tres-cents alumnes. Cfr. «Empresas principales», una relació d'empreses amb més de cinquanta treballadors que constaven el 31 de desembre de 1971, PSUC, uc. 1636, c. 133, ANC.

35 Josep SerRAdelL, «Carta de Miró», 21 febrer 1972, NyR, Catalunya, c. 59, cp. 5, AHPCE. 
Al llarg d'aquell matí, com s'ha mencionat, els estudiants van realitzar diversos intents de manifestació al carrer. Uns cinc-cents alumnes van aconseguir fer una seguda al Balcó del Mediterrani, en la qual «los grises cargaron brutalmente, dispersándolos». Llavors, un centenar d'estudiants van reagrupar-se a la catedral en disposició d'ocupar-la. «Los grises penetraron en la catedral, pistola en mano, y la desalojaron practicando 16 detenciones». ${ }^{36}$ Alguns dels detinguts van ser alliberats després de la mediació d'un clergue que es va presentar a la comissaria. A més del sacerdot, alguns professors dels detinguts també van comparèixer davant la policia per exigir l'alliberament dels seus estudiants. Quan la força pública els ho va denegar, van decidir que ocuparien la catedral, però finalment la policia va deixar els joves en llibertat i no va creure's necessari produir cap ocupació. La participació del professorat d'ensenyament mitjà en les protestes no va ser un cas aïllat per la precarietat laboral que patien, ja que es calcula que el $80 \%$ eren no numeraris. ${ }^{37}$

Això va succeir durant el matí. A la tarda es va organitzar una nova manifestació, els actius de la qual estaven certament més minvats. Tot i això, prop de tres-cents estudiants van manifestar-se per la Rambla Nova sense que la policia armada i la guàrdia urbana hi intervinguessin (simplement es dedicaren a desviar el trànsit perquè passés la manifestació).

A Reus, on el contingent d'estudiants era menor que el de Tarragona, el seguiment de la vaga es va circumscriure a uns cent cinquanta estudiants d'institut i uns cent alumnes de formació professional. A l'institut, els nois van haver de plantar cara als professors, que, al contrari que a Tarragona, van oposar-se frontalment a la protesta. Els piquets no van poder accedir a l'institut, ja que els docents havien tancat el reixat amb clau, i van optar per fer una assemblea en ple carrer. Els joves anaven explicant als transeünts els motius de la vaga fins que, finalment, van ser dissolts per la policia, que havia estat advertida pel director del centre. A l'escola de mestria industrial, un militant de la JCC havia realitzat un míting davant dels seus companys de grup nocturn del dia anterior - la majoria eren joves treballadors - i van decidir que secundarien la vaga: 
la van abonar un centenar. A més de l'institut i de l'escola de formació, van sumar-s'hi centres privats com La Salle — amb el beneplàcit de la direcció del centre- i, fins i tot, un collegi femení de monges. La idea inicial dels estudiants era recórrer en una manifestació el carrer de Monterols, però «fue tomada por los grises», per la qual cosa van optar per fer una volta i es van acabar concentrant a la veïna plaça de Prim, juntament amb dos-cents treballadors que s'havien solidaritzat amb els estudiants. ${ }^{38}$

CCOO havia secundat la vaga dels batxillers, un fet que va palesar la nodrida presència de treballadors al carrer. El PSUC va fer una lectura entusiasta dels esdeveniments del 14 de febrer. ${ }^{39} \mathrm{El} 8$ de març, CCOO va convocar una jornada de lluita en què es fonien les reivindicacions laborals amb les del programa dels batxillers. Per a aquell dia el moviment estudiantil havia convocat una nova acció general contra la LGE, amb una forta càrrega antirepressiva. ${ }^{40}$ Per al PSUC, la unió en la lluita de les reivindicacions obreres i dels treballadors intellectuals era la plasmació pràctica de la seva aliança política de les forces del treball i de la cultura. ${ }^{41}$ Tot i que no disposem de dades sobre el desenvolupament i el seguiment de les vagues del 8 de març a Tarragona, el desplegament de la LGE va seguir motivant mobilitzacions de diversos tipus durant anys posteriors: mítings celebrats obertament a la ciutat (gener del 1973), vaga de cuidadors i boicot als autobusos a la Laboral (maig del 1973), proliferació d'assemblees d'estudiants a la universitat (maig i juny del 1973, febrer del 1974), articulació d'un moviment estudiantil a l'institut Martí i Franquès (el març del 1974 emeteren el seu primer comunicat), elaboració d'un programa reivindicatiu unitari entorn del boicot a la selectivitat, etc. ${ }^{42}$

38 Josep SeRradelL, «Carta de Miró», 21 febrer 1972, NyR, Catalunya, c. 59, cp. 5, AHPCE.

39 «14 de febrero: gran paso adelante en la movilización y organización de masas hacia la Huelga Nacional», març de 1972, Fons Centre del Treball i Documentació (CTD), PSUC, c. 3, Arxiu Històric de la Comissió Obrera Nacional de Catalunya (AHCONC).

40 Cartes de Martín (Gregori López Raimundo) i de Miró (Josep Serradell), març de 1972, NyR, Catalunya, j. 2323, AHPCE.

41 «A los trabajadores, a los estudiantes, a todo el pueblo de Tarragona», CL de Tarragona del PSUC, 5 març 1972, PSUC, uc. 940, c. 54, ANC. En bolígraf hi ha anotat que se’n van repartir quatre mil còpies.

42 Cfr. Heras 1991, 106 i s. 
La JCC va ser en gran part la responsable d'eixamplar el moviment estudiantil cap als centres d'ensenyament mitjà, que, al mateix temps, van engrandir la JCC. Després de les mobilitzacions del febrer i del març del 1972, els comunistes tarragonins disposaven de cèllules a tots els centres d'educació mitjana i superior, amb la sola excepció de La Salle. Els batxillers comunistes van impulsar la formació de comissions de centre, que a l'estiu constituien ja una coordinadora entre les CEB de Reus i Tarragona. ${ }^{43}$ Una de les principals denúncies va ser la manca de places educatives per als batxillers, a causa de l'escassetat de centres de formació. Aquella realitat obligava el jovent rural a desplaçar-se cada dia a les ciutats properes, amb el cost addicional que això suposava per a les famílies, i deixava fora dels centres molts estudiants dels districtes obrers superpoblats. El motiu últim en ambdós casos era el mateix: la manca d'inversions en infraestructures educatives, ja que les Corts havien tombat el gravamen fiscal a les rendes altes que havia de finançar la LGE. ${ }^{44}$ Es denunciava, a més a més, l'existència de «llistes negres» dels estudiants que havien destacat els anys anteriors en les lluites contra la LGE i als quals se'ls denegava l'ingrés als instituts. ${ }^{45}$

La JCC de les comarques de Tarragona havia liderat el conflicte als instituts d'ensenyament mitjà en més de trenta centres, com també a la universitat. Com pot apreciar-se, per la gran varietat de centres que van secundar la vaga — des de collegis de formació per a obrers fins a collegis privats i religiosos-, el conflicte va ser molt transversal, i el lideratge que va exercir la JCC i el prestigi que va guanyar-se entre els estudiants la van posar en disposició de realitzar actuacions molt més àmplies en el futur. Una bona mostra d'això és la reunió que es va organitzar a l'Aleixar (Baix Camp), en la qual van participar més de cinc-cents estudiants de totes les comarques tarragonines amb la finalitat de tractar de la problemàtica del sector estudiantil. ${ }^{46}$

43 Josep Roure (Josep PardelL), «Informació de Tarragona», 27 febrer 1972, NyR, Catalunya, j. 2380, AHPCE.

44 Colomer 1978, 55-56.

45 «I Conferencia Nacional», informe del CC de la JCC presentat per Llorenç Grau, agost de 1973, PSUC, uc. 1271 (III), c. 75, p. 9, ANC.

46 Josep Roure (Josep PardelL), «Algunes informacions de les Organitzacions del Partit a Comarques», abril de 1973, NyR, Catalunya, c. 63, cp. 1/1, AHPCE. 
El 1974 va ressorgir el conflicte estudiantil, esperonat de nou per la selectivitat. Es denunciava la construcció d'una universitat elitista amb el subterfugi que estava massificada. També es reivindicaven la supressió de la selectivitat i la completa gratuïtat de la universitat; es reclamava l'elaboració democràtica dels plans d'estudis amb la collaboració de professors i estudiants, i s'exigia l'amnistia als damnificats per motius polítics (les referides «llistes negres» d'alumnes i també de docents) i el dret de reunió i d'associació, tant del professorat com de l'alumnat. A Tarragona, els professors d'institut van redactar un escrit conjunt en què s'oposaven a la selectivitat i demanaven democratitzar el COU. Parallelament es van fer diverses assemblees de batxillers, en què es va decidir manifestar-se per la ciutat. La comunitat universitària també va sumar-se a les protestes, i el 9 de maig de 1974 van secundar la nova vaga general universitària; les facultats de Lletres i Ciències quedaren completament aturades, i els universitaris, juntament amb els batxillers, van manifestar-se per la Rambla Nova de Tarragona. ${ }^{47}$

Al costat de la JCC hi havia altres grups que tenien el moviment estudiantil com a espai d'actuació preferent. La Lliga Comunista (LC) - el partit fundat el 1972 sobre l'escissió de la tendència Encrucijada de la Lliga Comunista Revolucionària— ${ }^{48}$ havia desenvolupat un paper important en les mobilitzacions contra la selectivitat el 1973, que van ocasionar el tancament de la universitat durant una temporada. El PCE (internacional), a través de la seva organització juvenil, la Jove Guàrdia Roja (JGR), va tenir una presència reduïda però molt influent a la Universidad Laboral — però cap a la delegació universitària des del setembre del 1973, quan els seus membres es van traslladar a Barcelona per finalitzar la llicenciatura. D'altra banda, el grup d'estudiants de la LC havia quedat gairebé desarticulat després de la detenció d'un dels seus dirigents al final del 1973 i la resta de l'agrupació es va integrar al PCE(i) l'abril del 1974. Tot i això, aquest sector universitari de la JGR va tenir una vida molt curta, perquè al final de l'any es va dissoldre dins el PSUC. 49

47 «Movimiento estudiantil: la lucha contra la selectividad», Lluita 13 (maig 1974).

48 Caussa \& Martínez i Muntada 2014, 27-28.

49 Heras 1991, 78.

FRANQUISME \& TRANSICIÓ 4 (2016) ISSN 2014-511X PUNCTUM, UNIVERSITAT OBERTA DE CATALUNYA \& FUNDACIÓ CARLES PII SUNYER 
Per tant, la JCC va contribuir a la irrupció del moviment estudiantil, que, alhora, va reforçar l'organització juvenil comunista, com també el partit. La importància, doncs, del moviment dels batxillers va ser la dimensió pública i no exclusivament reclosa en el seu espai de desenvolupament natural: l'institut. Contràriament, la mobilització dels batxillers, al costat del moviment universitari tarragoní — estretament lligat a grups barcelonins que van contribuir a estendre les reivindicacions més enllà de la Gran Barcelona-, va disputar el control de l'espai públic a les autoritats franquistes locals. Entre el 1972 i el 1974 les manifestacions estudiantils es van duplicar, al mateix temps que la conflictivitat sociopolítica en general va augmentar d'una manera notòria. Les empreses que van protagonitzar més conflictes van ser les del ram del metall i de la construcció, tot i que la irrupció d'una conflictivitat inèdita en indústries que fins aleshores no havien destacat per la combativitat posava de manifest la imperícia de la dictadura per desactivar-ne la contestació, com també la capacitat de l'antifranquisme per mobilitzar cada cop segments de la societat més grans.

\section{L'establiment de les bases d'un moviment juvenil de masses (1970-1974)}

L'octubre del 1970, el Comitè Executiu provisional de la JCC havia emès una resolució en la qual considerava que «en el actual marco, donde la ofensiva de la clase obrera es el exponente más destacado, el esfuerzo de la juventud comunista debe redoblarse en todos sus frentes». Calia estendre les activitats de la JCC a nous sectors del jovent que encara no s'haguessin incorporat a la lluita antifranquista (és a dir, el jovent obrer i els universitaris); per això s'esperonava els militants a ser audaços i a promoure noves formes d'organització i de coordinació capaces de sumar-hi un contingent elevat de joves en virtut de la seva condició de joves i no estrictament com a militants d'organitzacions antifranquistes. A banda de l'obrer, els batxillers eren identificats com a front de treball imprescindible (tal com, en efecte, ho serien). Tanmateix, el proselitisme no es podia reduir a l'àmbit estudiantil, ja que la problemàtica pagesa havia d'ésser també un camp de batalla preferent de la JCC en conjunt i no 
únicament de la de les zones rurals. El treball del jovent dins les Forces Armades, d'altra banda, era considerat un front prioritari, perquè l'èxit de «disputar el Ejército a la dictadura» era una condició necessària perquè reeixís la vaga nacional que havia de posar fi al franquisme..$^{50}$

Des del naixement, la JCC va tenir una clara vocació unitària i una línia política molt definida en aquest sentit. A l'inici havia de seguir l'empremta de la Comissió Coordinadora de Forces Polítiques de Catalunya (CCFPC) i d'avançar en allò que els comunistes anomenaven Pacte per la Llibertat. S'instava la militància «a realizar los esfuerzos que nos conduzcan a dicho pacto A TODOS LOS NIVELES». ${ }^{11}$ El Pacte per la Llibertat tenia elements de convinença transitòria per posar fi a la dictadura. No podem, però, entendre'l en exclusiva com un compromís tàctic i, per tant, provisional entre les forces obreres i burgeses que no hauria d'estendre's més enllà de la restauració d'un sistema democràtic. Hi havia un matís important. Per als comunistes resultava evident que el Pacte per la Llibertat «no se firmará jamás si no se consigue un movimiento de masas tan potente, decidido y estructurado, con unos objetivos tan claros que los evolucionistas sientan que toda traición a un movimiento así equivale a un suicidio político».52 Era fonamental, doncs, que el moviment de masses tingués clars els seus objectius, per tal d'assegurar-hi una traducció eminentment política a llur acció i que la seva potència no fos estèril. En aquest sentit, no s'entenia el pacte com un mitjà «para desencadenar un gran movimiento de masas, sino para garantizar el mayor desenlace posible a un movimiento que ya está en marcha».53 És a dir, allò fonamental del Pacte per la Llibertat era l'acció de la massa unitària: fer convergir en un sol torrent totes les forces que s'oposaven a la dictadura, parafrase-

50 «Resolución del Comité Ejecutivo Provisional de la JCC», octubre de 1970, PSUC, uc. 1272, c. 76 , ANC.

51 «esolución de la Dirección Provisional de la JCC», febrer de 1970, PSUC, uc. 1272, c. 76, cp. 1, ANC.

52 Molinero \& Ysàs $(2010,359)$ indiquen que el terme evolucionista en aquest context ha d'entendre's com aquelles persones que estarien en disposició o que hauríen abandonat el règim, com també les que estarien en la frontera de la dissidència, i no com els sectors interns del règim que pretendrien liberalitzar-lo.

53 Joaquim Sempere, «El Pacto para la Libertad y sus implicaciones», treball d'Ernest per a la consideració del Comitè Executiu, setembre de 1970, NyR, Catalunya, c. 59, cp. 2, AHPCE. La cursiva és meva.

FRANQUISME \& TRANSICIÓ 4 (2016) ISSN 2014-511X PUNCTUM, UNIVERSITAT OBERTA DE CATALUNYA \& FUNDACIÓ CARLES PII SUNYER 
jant la cèlebre locució de López Raimundo. ${ }^{54}$ Convé, però, diferenciar-lo respecte de la proposta estratègica d'Aliança de les Forces del Treball i la Cultura, l'objectiu de la qual era la transformació a llarg termini de les estructures socioeconòmiques en un sentit socialista. ${ }^{55}$

Però des de quines bases podia promoure's el moviment juvenil de masses? Com s'ha mencionat més amunt, preferentment des dels espais juvenils: els clubs, les penyes, els centres socials, els centres educatius i els llocs de treball (tot i que no es tractava tan sols de practicar l'entrisme dins d'aquestes estructures prèviament existents, sinó que calia anar més enllà). El jovent comunista havia de propiciar l'existència de com més bases millor, a partir de les quals el moviment pogués arrelar, desenvolupar-se i connectar amb la resta de l'antifranquisme. ${ }^{56}$ En efecte, en parallel a la formació de l'Assemblea de Catalunya al llarg del 1971, la JCC va iniciar contactes amb organitzacions juvenils d'altres formacions polítiques per constituir una plataforma juvenil unitària. La idea consistia a aconseguir «una coordinació amb altres grups d'incidència juvenil que no necessàriament fossin polítics».57 Però el problema era com es concretava una plataforma de coordinació de grups no polítics de la societat civil i d'organitzacions antifranquistes sense cap base programàtica mínima, que a priori no es volia establir per no posar portes al camp. La proposta va sorgir d'unes primeres trobades bilaterals celebrades al final del 1971 entre la JCC i la Joventut Obrera del Front Nacional de Catalunya (FNC). A inicis del 1972 s'hi va sumar també la JGR. Bandera Roja, però, no va ocultar el desinterès pel tema i el Partit Socialista d'Alliberament Nacional (PSAN) va participar com a observador en unes primeres i poc fructíferes trobades en l'àmbit català..$^{8}$

54 Gregori López Raimundo, «Fem convergir en un sol torrent les forces que s'oposen a la dictadura», V Reunió Plenària del CC del PSUC, setembre de 1970, PSUC, c. 4, ANC.

55 Sobre l’Aliança de les Forces del Treball i la Cultura i la seva ambivalència durament criticada pels intellectuals del partit, cfr. PALA 2016, 124-129.

56 «Conclusión a la discusión del II Pleno Ampliado del Co. Lo. de la Juventud Comunista», gener de 1972, OOJJ, JCC, c. 154, AHPCE.

57 «lataforma de joventut», s.d. [post. des. 1971, probablement gen.-març 1972], PSUC, uc. 1301 (I), c. 86, ANC.

58 Ibídem. 
La JCC de Terrassa - l'avantguarda indiscutible del moviment juvenil a Catalunya - va mostrar el camí a seguir. La primavera del 1972, poc després de la primera reunió bilateral JCC-FNC, els terrassencs van impulsar un festival de clubs juvenils en què van participar joves de diferents organitzacions i d'altres sense filiació militant. Segons els organitzadors, aquella havia estat una «buena experiencia que nos demuestra cómo la mayoría de las veces, dejando a un lado las discrepancias finales de política partidista que ahora no tienen consecuencia directa, se pueden buscar otros más inmediatos en los que todos estemos de acuerdo; que al mismo tiempo es un trabajo que acelera la unidad, indudablemente también acelera la lucha de toda la juventud contra la dictadura y por las libertades democráticas».59 Arran d'aquella vivència, la coordinadora de clubs juvenils que s'havia format amb anterioritat al festival va adquirir un «prestigio cara a otros centros que ya han pedido su participación en la misma. Así vamos forjando poco a poco un amplio frente de lucha democrática en Terrassa dispuesto a responder a cualquier consigna dirigida contra el sistema totalitario franquista. No hay que olvidar que nuestra política es ante todo de alianza con todas las fuerzas que se oponen al régimen de Franco». ${ }^{60}$ D’aquella experiència, n'aprendria el jovent tarragoní.

En efecte, el desenvolupament sostingut de l'antifranquisme a Tarragona durant els anys 1970-1972 - tot i la repressió, com veurem tot seguit-, el lideratge que havien adquirit els joves comunistes amb el conflicte dels batxillers i la penetració reeixida en les juntes de les organitzacions juvenils legals van empènyer la JCC a crear un organisme de coordinació de tots els clubs i centres juvenils de la ciutat. ${ }^{61}$ En un altre nivell, les Comissions Cíviques de Tarragona havien reunit des del 1967 partits, sindicats i personalitats a títol individual i actuaren com a primer punt de trobada de l'oposició al règim de la ciutat. Els principals impulsors foren mossèn Josep Asens, de la Germandat Obrera d'Acció Ca-

59 «Informe político de la Juventud Comunista sobre el $1^{\circ}$ Festival de Clubs Juveniles», Comitè de Barris de la JCC de Terrassa, 23 maig 1972, OOJJ, JCC, c. 157, AHPCE.

60 Ibídem.

61 «I Conferencia Nacional», informe del CC de la JCC presentat per Llorenç Grau, agost de 1973, PSUC, uc. 1271 (III), c. 75, ANC. 
tòlica (HOAC, en castellà); Ramon Dolç Gutiérrez, com a independent, i, pel PSUC, Rafael Nadal, Paco Martínez i l'històric Leandre Saún. El 1970 la Cívica es va descentralitzar i se'n va crear una a Torreforta, formada per dotze persones, i una altra a Reus, en la qual participaren comunistes, socialistes, cristians, i que la documentació qualifica, sense més, de «demòcrates». ${ }^{62}$ Amb la collaboració de l'advocat Rafael Nadal, Pedro Quintero i, especialment, Enrique de Gràcia, el juliol del 1972 s'impulsà l'Assemblea de Catalunya a Tarragona, òrgan al qual les Comissions Cíviques s'uniren com a representants dels intellectuals de la ciutat. ${ }^{63} \mathrm{El}$ secretariat permanent estava format per tres comunistes, un socialista i un representant del moviment veïnal, però no hi havia cap representant de la joventut antifranquista: Enrique de Gràcia pel PSUC, el paleta Manuel Martín Bravo per CCOO, el professor de química Pedro Quintero per les Comissions Cíviques, el llibreter Ramon Marrugat pel Moviment Socialista de Catalunya (MSC) i el sacerdot jesuïta Francesc Xammar per les Comissions de Barri. ${ }^{64}$ Malgrat l'absència de la JCC en la permanent, sí que hi eren com a membres de l'Assemblea de Tarragona. De fet, l'ampliació de l'Assemblea els anys següents es va produir en gran part a través de la JCC, ja que els seus militants van propiciar que les entitats juvenils de les quals formaven part s'adherissin a l'organisme.

Seguint el model terrassenc, el jovent comunista de Tarragona va centrar els esforços a constituir una coordinadora juvenil d'àmbit local. Allò fonamental era l'acció, el proselitisme i l'articulació d'un teixit social prou dens per anar bastint un moviment juvenil de masses antifranquista. ${ }^{65}$ En conseqüència, la intensa activitat pública de la JCC tarragonina no va passar desapercebuda a les autoritats. Els mesos de juliol i setembre del 1971, les organitzacions de Tarragona i Reus van patir un parell de caigudes d'importància. En la darrera, la nit del 26 de setembre, foren sorpresos mentre realitzaven una gran pintada contra les eleccions

62 Josep Serradell, «Carta de Miró», 6 febrer 1970, NyR, Catalunya, c. 59, cp. 1, AHPCE.

63 Entrevista a Pedro Quintero, 17 gener 2008. Agraeixo a Marc Suanes l'accés íntegre a les entrevistes que va fer a Pedro Quintero i a José Estrada durant la seva investigació i que actualment són accessibles al Fons Sonor (FS) de l'Arxiu Històric de la Ciutat de Tarragona (AHCT).

64 Marrugat 2012, 164.

65 «Charla con camaradas de Madrid y Cataluña», Horizonte 9, segona època (des. 1971). 
a Corts i van ser detinguts Josep Colomé, Amadeu Bonet, Ramon Lloc, Arcadi Vilella i Jordi Becaria, tots ells quadres locals de la JCC. ${ }^{66}$ Aquelles detencions, i el sever maltractament físic i psicològic a què van ser exposats els joves a comissaria, posaven sobre la taula la brutalitat del règim i la necessitat d'extremar les precaucions. Però també van brindar l'oportunitat per cercar la solidaritat popular i ampliar el moviment antifranquista. Aviat es va formar el Comitè Jovenívol de Solidaritat de Reus i comarca, ${ }^{67}$ l'acció del qual va consistir a reunir un ajut econòmic per a les famílies dels detinguts, estendre les demandes d'amnistia i portar als tribunals els membres de la força pública responsables de les tortures. Sota l'assessoria de Rafael Nadal es va aconseguir que els policies Atilano del Valle, Juan Aguilar i Emilio Rabanete fossin sancionats pels maltractaments. ${ }^{68}$ D'altra banda, a la JCC li urgia trobar formes d'actuació pública que fossin capaces d'esquivar la repressió franquista i que alhora no l'allunyessin de la massa juvenil. És en aquest doble sentit — mantenir-se dins el moviment de masses i evitar la repressió- que cal comprendre l'esforç de coordinació local dels clubs juvenils de Tarragona el 1972.

Malgrat aquell èxit, que establia les bases de l'ulterior creixement i la influència de l'organització, els comunistes en conjunt seguien tenint grans dificultats per arrelar entre altres sectors socials fora de la classe obrera industrial, dels estudiants i de certs sectors intellectuals. Llevat dels casos de Lleida i d'Amposta, el moviment camperol d'orientació comunista era més retòric que real abans del 1970. ${ }^{69}$ Tot i això, la presència comunista entre els treballadors no era una relació necessària, i darrere de cada nou militant hi havia un gran esforç de proselitisme i de mobilitzacions braç a braç. L'arrelament de la JCC en la Tarragona industrial d'aleshores era, amb tot, encara modesta: durant l'anomenada «promo-

66 EscodA 2007, 14. Els detinguts, el 21 de juliol, foren Daniel Espuny Robles i el seu germà Josep, Julio Dueñas, Àngel Fernández i un altre jove comunista de Torreforta que no he aconseguit identificar, juntament amb el militant del PSUC Josep Poget Ferré.

67 «Després de la Festa de la Llibertat», Nova Falç s.n. [1] ([set.] 1971).

68 «Informe sobre el juicio realizado en Reus a tres policías acusados de torturas», 9/1972, NyR, Catalunya, j. 2386, AHPCE.

69 Sobre el cas d'Amposta, cfr. FerRer GonZÁlez 2014, 67-82. Actualment preparo un article sobre la contribució del PSUC al sorgiment d'un nou moviment pagès a Catalunya.

FRANQUISME \& TRANSICIÓ 4 (2016) ISSN 2014-511X PUNCTUM, UNIVERSITAT OBERTA DE CATALUNYA \& FUNDACIÓ CARLES PI I SUNYER 
ció Lenin» només setze militants s'havien incorporat a les seves files. ${ }^{70}$ Però la situació va canviar de manera accelerada en poc temps: el cercle de nous militants de la JC que s'havia format a Reus en dates properes al Primer de Maig del 1970 i que va tenir un «bautismo de fuego» amb una gran pintada a la rodalia de la ciutat; ${ }^{71}$ l'aparició del butlletí Demà; la participació decisiva del jovent comunista en el moviment estudiantil, i la realització d'activitats i actes multitudinaris com la Festa de la Llibertat, que va reunir tres-cents joves a Tarragona l'agost del $1971 .{ }^{72}$ Tot plegat va fer que en poc més d'un any la JCC tarragonina tingués més militants i presència social que el PSUC.73

En efecte, l'activitat desplegada per la JCC no se circumscrivia només a les ciutats de Reus i Tarragona i a les seves barriades, sinó que, progressivament, es va anar estenent pel Camp de Tarragona. El motiu no era cap altre que el prestigi que la JCC havia adquirit mitjançant l'organització d'excursions al camp i trobades de naturalesa diversa - esportiva, recreativa, cultural... - que tenien la capacitat de mobilitzar centenars de joves d'ambdós sexes i d'extracció social diversa: molts d'ells eren obrers i fills d'obrers, però n'hi havia un segment significatiu que eren joves rurals i camperols. ${ }^{74}$ Resulta evident que el creixement qualitatiu, tant de les actuacions del moviment juvenil com de la JCC, tenia relació amb la ja esmentada coordinació de clubs juvenils. Aquella coordinació local, que els va permetre disposar d'una estructura legal per organitzar trobades, excursions o, fins i tot, festes; obtenir finançament públic de l'ajuntament i fer ús dels locals de la falangista Organización Juvenil Española (OJE), també permetia minimitzar els riscs repressius. A més, i aquesta és una característica específica de la JCC tarragonina, el desplegament d'activitats amb una dimensió que ultrapassava la ciutat, va facilitar el

70 «La campanya per un Partit més fort i arrelat a les masses i el treball d'organització», 1970, PSUC, uc. 407, c. 15, ANC.

71 «Nosotros, jóvenes nacidos después del 39...», informe presentat per la Comissió Auxiliar del PSUC en la reunió plenària de la JCC, 7/1970, MIT, GE, Comunismo, c. 42/9097, cp. 6, AGA.

72 «Festa de la Llibertat», Demà 7 (set. 1971).

73 DOMÈnech 2008, 114.

74 Josep Roure (Josep PARDELL), «Algunes informacions de les organitzacions del Partit a Comarques», abril de 1973, NyR, Catalunya, c. 63, cp. 1/1, AHPCE. 
foment de l'organització entre joves pagesos o fills de pagesos, un dels sectors que el partit intentava sumar a la seva aliança antifranquista. ${ }^{75}$

La consigna de la JCC per al camp era clara: calia que «las organizaciones de la Juventud Comunista lleguen más profundamente al campo, que dediquen más atención a los problemas campesinos, que los conozcan mejor y adopten un plan de acción entre las masas juveniles campesinas». ${ }^{76}$ La problemàtica pagesa havia de ser un camp de batalla preferent de la JCC en conjunt, i no només de la de les zones rurals. ${ }^{77}$ El PSUC creia que la JCC podia ser l'element dinamitzador de les CCPP. ${ }^{78}$ Les CCPP, que eren l'intent d'organitzar el descontentament camperol seguint un model similar al de CCOO, aspiraven a impulsar un nou moviment pagès. ${ }^{79}$ Si bé aquestes comissions havien gaudit d'una sèrie d'èxits inicials, després de l'estat d'excepció del 1969 havien quedat en una situació d'atonia i els primers anys setanta eren de crisi oberta. Un dels problemes principals de les CCPP era la incapacitat d'anar més enllà d'elles mateixes, més enllà de la seva (ja en si petita) base d'activistes, la majoria d'ells vinculats excessivament al PSUC, als ulls de molts pagesos. En aquest sentit, la JCC de Terrassa havia començat a transitar la llera que d'altres seguirien:

En aquest període, algunes organitzacions han començat a editar propaganda per dur-la a altres indrets de Catalunya. Això és tan important que tenim a Catalunya zones, especialment pageses, mancades de l'organització del Partit, la qual cosa suposa que la nostra política és encara inconeguda en l'essència a llocs importants, que milers de catalans no han tingut oportunitat de llegir, d'estudiar la nostra política, de veure les nostres solucions i de meditar sobre

75 Entrevista a Andreu Mayayo i Artal, 6 setembre 2016. L’òrgan de la UJCE ja destacava aquesta especificitat de la JCC tarragonina en un número del final del 1971; cfr. «Charla con camaradas de Madrid y Cataluña», Horizonte 9, segona època (des. 1971).

76 «Resolución de la Dirección Provisional de la JCC», febrer de 1970, PSUC, uc. 1272, c. 76, cp. 1, ANC.

77 «Resolución del Comité Ejecutivo Provisional de la JCC», octubre de 1970, PSUC, uc. 1272, c. 76, ANC.

78 «Contra el continuismo: por un cambio que asegure las libertades democráticas y nacionales de los Pueblos de España», declaració del CC del PSUC, setembre de 1971, CTD, PSUC, c. 59, cp. 1, p. 6, AHCONC.

79 Cfr. Ferrer GonZÁlez 2016. 
com poden organitzar-se en la defensa del seus interessos i lluitar contra el règim franquista.

D’una forma especial caldria que certes organitzacions estudiessin la manera de fer arribar als pobles essencialment pagesos LA VEU DEL CAMP i en general la premsa del partit. Això seria d'un gran ajut pel moviment pagès, per la lluita general contra la dictadura. En aquest ordre cal destacar la iniciativa del comitè K-2 de la JC de Terrassa, que va organitzar una sortida d'uns cinc pobles dels voltants de la ciutat per distribuir propaganda del partit i realitzar una nodrida pintada contra la repressió. Aquest és un exemple que caldrà multiplicar. $^{80}$

En efecte, Terrassa marcava novament el camí, però la JCC tarragonina va arribar més lluny en aquest aspecte. Durant el VI Ple Ampliat del Comitè Central del PSUC, celebrat el setembre del 1971, Isidor Boix donava motius per ser optimista amb el desenvolupament de la JCC més enllà de la Gran Barcelona. En destacava el creixement i la consolidació amb la incorporació de quatre-cents trenta nous militants durant la promoció Lenin: «ocupa el primer puesto en cifras absolutas la JC de Tarrasa, seguida por la de Barcelona, la de Mataró y la de Reus-Tarragona, comarca esta última en la que las formas de trabajo y la incidencia en numerosos pueblos, a través de su organización y de su periódico Demà, es un ejemplo a seguir». ${ }^{81} \mathrm{~A}$ més, de Demà en destacava també «el reciente suplemento Nova Falç, dirigido a la juventud campesina recogiendo sus problemas, hecho por corresponsales en los pueblos de la zona». ${ }^{82}$ Sovint, les corresponsalies que elaboraven els continguts de la premsa servien per estructurar la JCC al Camp de Tarragona, en especial als pobles petits. Molts joves comunistes que no tenien vies de participació política a les seves localitats trobaven sentit a la militància gràcies a l'elaboració collectiva del butlletí intercomarcal de la JCC. De bon començament, Demà va do-

80 «La campanya per un Partit més fort i arrelat a les masses i el treball d'organització», 1970, PSUC, uc. 407, c. 15 , p. 44 , ANC.

81 Ignasi Bruguera (Isidor BoIX), «El reforzamiento del partido y las cuestiones de organización», informe en el III punt de l'ordre del dia del VI Ple Ampliat del CC del PSUC, setembre de 1971, CTD, PSUC, c. 59, cp. 1, p. 5, AHCONC.

82 Ibídem, 12. 
nar cabuda a problemàtiques pageses i va imbricar-les amb les problemàtiques generals del jovent. Així, en les seves pàgines es va poder seguir el desenvolupament de les anomenades «guerra de la llet» $\mathrm{i}$ «guerra del pebrot». ${ }^{{ }_{3}}$ A més, entre les seccions habituals hi havia l'esmentada Nova Falç, la qual aviat es va convertir en el butlletí independent de la Joventut Comunista Camperola. ${ }^{84}$ Aquest va ser, amb tota seguretat, el nom que rebia el front de treball específic de la JCC al camp, més que no pas una organització de joves pagesos comunistes, una classe que aleshores era prioritària en la política d'aliances dels comunistes.

En l'aspecte merament polític, la JCC va fer un esforç per atreure les diverses organitzacions antifranquistes que anaven sorgint cap als posicionaments de l'Assemblea de Catalunya. Ja abans de la constitució de la Junta Democràtica d'Espanya (JDE), el juliol del 1974, les joventuts comunistes havien realitzat la seva fórmula d'Aliança Democràtica Juvenil (ADJ). ${ }^{85} \mathrm{El}$ 1971, la UJCE madrilenya havia endegat un projecte d'ADJ que englobava les joventuts socialistes, grups catòlics i, fins i tot, sectors carlins. La UJCE semblava entendre l'ADJ com una mena d'enclavament estratègic que havia de desenvolupar el seu paper «no sólo en la liquidación del franquismo, sino en la preparación de etapas posteriores». ${ }^{86}$ Evoca la imatge d'una sort de JSU per atreure els integrants cap als seus posicionaments estratègics. Això no obstant, la JCC entenia que l'ADJ havia de ser més aviat un moviment social - o sociopolític - que una plataforma de direcció política; sense entrar ni tan sols a concebre-la en termes estratègics de transició cap al socialisme, sinó com a front (ampli) de coordinació antifranquista. A partir de la constitució de la JDE l'estiu del 1974, la JCC va realitzar una formulació més precisa sobre l'AJD. La proposta de la JCC consistia a «impulsar un frente, un movimiento amplio de agrupaciones, entidades, organizaciones (tanto legales como ilegales) que a pesar de sus diferencias entre sí puedan ponerse de acuerdo para la realización de actos multitudinarios de acentuado carácter democráti-

83 Demà 10 (juny-jul. 1971). Sobre les anomenades «guerres agràries», cfr. ALONSO 1976, 55-132.

84 Demà 7 (set. 1971); Nova Falç s.n. ([set.] 1971).

85 No s'ha de confondre amb l'Associació Democràtica de la Joventut impulsada pel PCE(i) com a proposta del front únic antifeixista per al jovent. Cfr. MARTín RAmos 2011, 145.

86 «Charla con camaradas de Madrid y Cataluña», Horizonte 9, segona època (des. 1971). 
co y progresista, y en la dirección de acabar con la dictadura franquista. Forjando en la práctica lo que entendemos como ADJ».87

Era una formulació molt similar a la que Joaquim Sempere havia fet anys enrere sobre el Pacte per la Llibertat: no es tractava d'endegar el moviment, atès que ja existia, sinó de dotar-lo d'una dimensió política i de masses. ${ }^{88} \mathrm{Amb}$ tot, la proliferació de noves organitzacions durant els primers anys de la dècada dels setanta a Tarragona va provocar que l'ADJ es trobés en competència, en el pla polític, amb altres sigles unitàries. En efecte, la JCC i la JGR van enfrontar-se en el camp unitari a través de llurs plataformes polítiques: l'ADJ i el que els joves maoistes anomenaven Joventuts Democràtiques (JJDD). Les JJDD eren la concreció del front únic del jovent antifranquista que preconitzava la JGR des de la seva formació, l'octubre del $1973{ }^{89} \mathrm{El}$ PCE(i) entenia que calia desbordar l'Assemblea de Catalunya mitjançant la formació o, en el cas que ja existissin —com a Tarragona-, la revitalització d'assemblees d'àmbit local. ${ }^{\circ}$ Molt probablement les experiències com les de Lleida, en les quals la JGR havia impulsat un organisme de coordinació de grups polítics amb la denominació Joventut Democràtica, en què participaven juntament amb la JCC, grups catòlics i carlins sota els punts de l'Assemblea de Catalunya, van conduir el PCE(i) a formular i difondre la proposta de JJDD els mesos següents..$^{91}$

La competència d'aquestes dues sigles en el camp unitari va ser més de caràcter teòric que pràctic. Es va gastar molta tinta a redós de la unitat juvenil tarragonina, si s'ha de jutjar per la documentació conservada. A diferència del cas lleidatà, la JCC havia estat marginada en la construc-

87 «Guión de discusión sobre la actividad unitaria de la JC de Catalunya», agost de 1974, PSUC, uc. 1300 (II), c. 85 , ANC.

88 Cfr. Joaquim Sempere, «El Pacto para la Libertad y sus implicaciones», treball d'Ernest per a la consideració del Comitè Executiu, setembre de 1970, NyR, Catalunya, c. 59, cp. 2, AHPCE.

89 «Bases provisionales de la Joven Guardia Roja», octubre de 1973, Fons JGRE, Organismos Centrales, Asociación por la Memoria Histórica del Partido del Trabajo y de la Joven Guardia Roja (AMH-PTE-JGR).

90 Joaquim BADIA, «Sobre la situación en Cataluña», III Ple del CC del PCE(i), dins Hacia el socialismo 4 (juny 1974 [abr. 1974]): 32-33, Fons PCE(i), Organismos Centrales, AMH-PTE-JGR.

91 «I Conferencia», informe del CC de la JCC presentat per Llorenç Grau, agost de 1973, p. 34-36, PSUC, uc. 1271 (III), c. 75, ANC; Entrevista a Carme Quinquillà Codina, militant de la JGR a Lleida, recollida a GALLEGO 1996, 197 . 
ció inicial de les JJDD i, quan va intentar formular per la seva banda l'ADJ, va topar amb la negativa aïrada de la JGR. ${ }^{22}$ Tot i els esforços dels joves comunistes a explicar el projecte d'ADJ, no van rebre cap resposta positiva. ${ }^{93}$ En un moment determinat es va proposar la fusió de les JJDD i de l'ADJ «en torno a un programa democrático y antifascista» concretat en els quatre punts de l'Assemblea de Catalunya i en dotze de la JDE i que, en el terreny local, l'organisme que se'n derivés pogués ingressar a l'Assemblea de Tarragona. L'objectiu era unir forces contra la dictadura i treballar per la vaga general política i la vaga nacional per posar fi al franquisme, i no encetar discussions teòriques alienes al jovent. ${ }^{44}$ La JCC devia voler introduir la seva concepció sociopolítica en el nou organisme, amb independència de les pretensions avantguardistes de la JGR.

La proposta de fusió d'ambdós organismes, però, no va ser ben rebuda per les JJDD. En una carta hilarant, les JJDD allegaven: «no pedimos a las $\mathrm{ADJ}$ de T. [Tarragona] que se fusionen con nosotros, ya que somos más realistas y vemos que lo que no está formado no se puede unir con JJDD». Concloïen en un clar to jocós: «creemos que os habréis dado cuenta de vuestro error y veréis claramente que si actualmente se quiere trabajar por la unidad de los jóvenes, hay que hacerlo en JJDD y no creando otros mov[imientos]. democráticos juveniles, que sólo harían que romper la unidad y crear un confusionismo entre la juventud». Finalment, es convidava la JCC a una reunió de les JJDD i a exposar les seves idees i a sotmetre-les a votació. 95 Clarament es va tractar d'un episodi localitzat en el temps i amb una escassa incidència en l'àmbit preferent de l'antifranquisme: els moviments socials. Atès que la discussió no conduïa enlloc, la resolució no es va donar per les lleres que havien endegat ambdues organitzacions, sinó en dos nivells diferents. D’una banda, es va aconseguir

92 Un jove militant de les Joventuts Socialistes rememorava la bona relació que ell mantenia amb la JGR i el sectarisme aïrat que aquests dispensaven, en canvi, contra els militants de la JCC. Entrevista a Josep Sánchez Cervelló, 20 juny 2016.

93 «Acerca de cómo entendemos los comunistas la unidad antifascista y por las libertades democráticas», carta dirigida a les JARC de Tarragona, s.d. [nov. 1974], PSUC, uc. 1300 (II), c. 85, ANC.

94 «Carta del Comité Local de Tarragona de la Joventut Comunista de Catalunya a las Juventudes Democráticas de Tarragona», 10 novembre 1974, PSUC, uc. 1300 (II), c. 85, ANC.

95 «Carta de la Comisión Permanente de las Juventudes Democráticas al Comité Local de Tarragona de la Juventud Comunista de Catalunya», novembre de 1974, PSUC, uc. 1300 (II), c. 85, ANC. 
resoldre-la en el terreny polític, amb les negociacions de les direccions de la JCC i la JGR, i, de l'altra i més important, la discussió va quedar enterrada per la dinàmica social que el moviment juvenil havia adquirit.

En l'àmbit polític, l'assumpte va quedar liquidat al final del 1974, quan es va celebrar una reunió a proposta de la JGR entre dos militants de les joventuts del PCE(i) i tres membres de l'executiva de la JCC. Un jove lleidatà de la JGR — probablement Andreu Rivadulla - va exposar en la reunió els objectius estratègics que l'organització maoista havia establert: impulsar la vaga general, en la qual el jovent tenia un paper fonamental; potenciar el moviment obrer, i forjar, juntament amb la JCC, un front antifranquista ampli per acomplir aquells objectius. Després d'un canvi estratègic, el PCE(i) havia decidit renunciar a la defensa política del front popular com a alternativa al franquisme. En aquell moment, les seves demandes coincidien amb les del PSUC i l'Assemblea de Catalunya: llibertats polítiques, amnistia i eleccions lliures. ${ }^{96}$ S'acordà que ambdues organitzacions juvenils impulsarien «organismos de base de la Asamblea en barrios, pueblos y comarcas», per dotar-la de més arrelament popular. La JCC va acceptar totes les formulacions de la JGR excepte la que feia referència a l'articulació de la unitat, ja que els maoistes consideraven que calia buscar-la «en la base de amplias organizaciones democráticas que configuren desde su constitución unos puntos mínimos de confluencia política y un firme deseo de lucha hasta el fin, unidos estrechamente a las organizaciones democráticas de todo el pueblo [... que] deberán tomar en sus manos [...] las reivindicaciones sociales de la juventud como parte inseparable de la lucha por la democracia».97

Era una concepció avantguardista que els comunistes sempre van pugnar per evitar en els espais unitaris, ja que no es tractava que les organitzacions assumissin les demandes del moviment, sinó que aquestes es fonguessin en el moviment. Es tractava de constituir un centre de coordinació dels moviments, no pas de direcció. Podem trobar discussions similars en el procés que donaria vida a la CCFPC el $1968.9^{8}$ El I Ple del

96 «Contactos Joven-Guardia (PCi) - Joventut Comunista de Catalunya», 28 octubre 1974, OOJJ, JCC, c. 154, AHPCE.

97 «Propuesta de comunicado conjunto JGR de C a las JC de C», s.a. [1974], uc. 1301 (I), c. 86, ANC.

98 Cfr. Pala 2011, 55. 
Comitè Nacional de la JCC, celebrat el novembre del 1974, va decidir que cada comitè local assignaria a un camarada la responsabilitat de les relacions unitàries. L'objectiu era guanyar adhesions i suport al programa de la JDE. Malgrat això, no se'ls escapava el fet que el marc unitari català era l'Assemblea i que aquesta encara no s'havia posicionat definitivament sobre la JDE. Amb tot, afirmaven:

El hecho de que en Catalunya la unidad pasa irreversiblemente por el marco de la Assemblea de Catalunya y que ésta todavía no haya manifestado su postura sobre la JD, nos obliga a utilizar los postulados de la AC para el establecimiento de mesas unitarias u otras coordinadas convergentes de la juventud. Lo que no priva en absoluto de hacer nuestro el programa de la JDE como alternativa política a nivel de todo el Estado español, al que con nuestro esfuerzo pretendemos se adhiera también la juventud catalana. ${ }^{99}$

Com hem vist, per a la JCC la unitat no era quelcom a traçar entre aparells d'organitzacions polítiques, tot i que no renunciava en absolut a pactes amb altres partits i organitzacions juvenils, «entendiendo que esta unidad se obtendrá fundamentalmente poniendo en pie, desarrollando y fortaleciendo al máximo los movimientos de masas de la juventud [...] como vía más eficaz para llegar a configurar un programa de lucha». És a dir, «nuestra aspiración prioritaria de estos momentos en nuestra relaciones con otras organizaciones democráticas y revolucionarias de la juventud [es] impulsar la movilización y la unidad de la juventud por la base, aprovechando al máximo todas las coberturas y posibilidades legales que nos permitan ir mucho más lejos y promocionando actos de masas unitarios en los que se reafirme la presencia democrática de la juventud». ${ }^{100}$

Una de les actuacions que la JCC s'havia proposat en l'àmbit unitari era estendre les «juntes democràtiques locals» 0 , en tot cas, difondre els dotze punts de la JDE. La resolució que es va aprovar en la XI Permanent

99 «La situación política y las tareas de la JC de Catalunya», informe presentat per Llorenç Grau en el I Ple del Comitè Nacional de la JCC, novembre de 1974, PSUC, uc. 1273, c. 77, p. 30-31, ANC.

100 Ibídem. 
de l'Assemblea de Catalunya va ser una dutxa d'aigua freda per als comunistes catalans. Tot i que s'hi instituïen els canals de comunicació bilaterals Assemblea-JDE, la Permanent s'oposava tant a la dissolució de l'Assemblea en la JDE com a l'entrada de la JDE a l'Assemblea. Es tancava, a més, la porta a l'existència d'altres organitzacions unitàries en territori català i, a més, no s'especificava si en el futur hi hauria la possibilitat d'establir contactes unitaris amb noves plataformes antifranquistes. ${ }^{101}$ La JCC, amb tot, va prosseguir la política d'ADJ, sostinguda en els moviments juvenils que havia impulsat: l'obrer, de batxillers, de pagesos, etc. Aquest era, al cap i a la fi, l'element que havia de marcar la línia unitària segons l'entenia la Joventut Comunista.

\section{El gran salt (1974-1976)}

Els dies 3 i 4 d'agost de 1974 va tenir lloc l'Acampada de la Joventut a la Conca de Barberà. Va ser organitzada per la JCC i hi van participar uns cent quaranta joves. «Las actividades fueron de lo más variado y al gusto de los jóvenes asistentes: juegos, 'foc de camp', diversas charlas sobre el trabajo, la emigración, la libertad, la sexualidad... en la que se llegaron a conclusiones de tipo político». ${ }^{102}$ Després de l'acampada, els joves van emprendre una caminada fins a Montblanc per assistir a un recital de Raimon, que va aplegar més de set-centes persones de totes les edats. Els diners recollits durant l'esdeveniment van ser destinats a ajudar els demòcrates xilens. Actes com aquell reforçaven les concepcions estratègiques de la JCC davant les dinàmiques més polititzants sostingudes per altres grups juvenils.

En el terreny polític, el 1974 fou un any de canvis. El mes d'agost, Andrés — nom de guerra de l'estudiant universitari Miquel Giribets - va ser designat responsable polític de la intercomarcal de Tarragona de la JCC. Aleshores la intercomarcal era responsable de les organitzacions juvenils comunistes de la majoria de comarques de Tarragona i dues de les quatre comarques de l'Ebre: Tarragonès, Baix i Alt Camp, Conca de Bar-

101 PALA 2011, 146-149.

102 «Acampada de la Joventut en la Conca», Demà 11 (ag.-set. 1974).

FRANQUISME \& TRANSICIÓ 4 (2016) ISSN 2014-511X PUNCTUM, UNIVERSITAT OBERTA DE CATALUNYA \& FUNDACIÓ CARLES PII SUNYER 
berà, Ribera d'Ebre i Terra Alta. Llavors al Priorat únicament existia organització del PSUC a Porrera i Marcà, amb una activitat escassa, i fins al 1976 no es va formar la JCC en aquells municipis. L'altra absència era el Baix Penedès, on no va existir organització de la JCC ni del PSUC fins que es van legalitzar el 1977. D'altra banda, el Baix Ebre i el Montsià es van organitzar al marge de Tarragona, ja que van formar la seva intercomarcal el 1976, tant de la joventut com del partit. ${ }^{103}$

L'organització de la ciutat de Tarragona es va mantenir en constant creixement per l'afluència permanent d'estudiants, que esdevenien un dels principals camps de reclutament de la JCC. D’altres que també hi ingressaven eren aquells que abandonaven les seves responsabilitats locals en la JCC i passaven a engrandir l'organització tarragonina. Aquest és el cas de Montblanc, ja que tots els membres de la JCC van marxar a estudiar a Tarragona l'octubre del 1974. Josep Andreu Domingo — fill de l'històric dirigent del FNC Antoni Andreu Abelló- n'era el responsable polític. Quan ell va marxar a estudiar a la ciutat, va cooptar un jove de quinze anys anomenat Andreu Mayayo perquè dirigís el comitè local, del qual també depenia l'organització de Blancafort. Assumida la direcció intercomarcal per Giribets, Josep Andreu va passar a responsabilitzar-se de l'organització a la ciutat de Tarragona. ${ }^{104}$

Miquel Giribets, cap de la intercomarcal, era també l'encarregat de l'elaboració i la impressió de Demà, que estrenava llavors la seva segona època. Durant el III Congrés del PSUC es destacava la continuïtat de Demà i dels seus suplements, Nova Falç i La Voz de la Juventud. ${ }^{105}$ A l'origen, Demà s'havia elaborat a Reus. Entre la seva aparició, a principis del 1971, i la partida del seu director, Josep Colomé, a fer el servei militar a la darreria del 1972, tenia una tirada modesta: al voltant d'una desena d'exemplars. La partida de Colomé, juntament amb les caigudes del juny i setembre del 1971, tal com s'ha comentat, va obrir un període en què la JCC del Camp de Tarragona va veure reduïda al mínim la seva vida orgànica - però no l'activisme dels militants a través dels clubs juvenils i en

103 Sobre la intercomarcal Baix Ebre-Montsià, vegeu FERrER GonZÁLEZ 2014.

104 Entrevista a Andreu Mayayo i Artal, 6 setembre 2016.

105 J. RÀFols, «La propaganda del PSUC», gener de 1973, NyR, Catalunya, c. 62, cp. 6/3, p. 23, AHPCE. 
els moviments socials, com hem pogut veure-, que s'allargaria fins a la formació del nou comitè intercomarcal el maig del 1974. Sota l'impuls de Giribets, hi van prendre una gran embranzida organitzacions com la de Torredembarra, dirigida per Josep Bargalló i Enric Bonan, i la de Reus, l'home clau de la qual fou Jordi Piqué, en substitució de Josep Colomé, que aleshores dirigia el comitè local del PSUC.

El 1974 també va ser un any que marcà el gran salt en termes de conflictivitat social. L’agitació laboral en indústries com Loste o Alena, empreses de nova construcció situades al polígon dels afores, inaugurava un període de pertorbació d'una ciutat que fins aleshores era identificada com «de funcionaris, capellans i militars». ${ }^{106}$ D’altra banda, les lluites veinals d'envergadura es van deixar sentir durant aquell any. Pel maig, un augment de preu dels bitllets va propiciar el boicot als autobusos a Bonavista, un conflicte que va derivar en el que alguns autors han considerat una autèntica vaga en l'àmbit local. ${ }^{107}$ Els dèficits d'infraestructures d'unes barriades que entre el 1971 i el 1975 van rebre l'afluència de més de vint mil persones van ser, tanmateix, un motiu de mobilitzacions constants durant aquells anys. ${ }^{108}$ Per exemple, l'atropellament mortal d'una dona i el seu fill de dos anys mentre esperaven l'autobús a la Floresta va provocar posteriorment que es fessin talls a la carretera de Reus-Tarragona per exigir la construcció d'un pont que hi passés per sobre. ${ }^{109} \mathrm{~A}$ la conflictivitat estrictament veïnal cal afegir-hi l'obrera, íntimament imbricades l'una en l'altra. Per exemple, quan les joves teixidores de Valmeline van fer una vaga de trenta dies que va implicar el $85 \%$ de la plantilla, el conflicte no es va circumscriure a la fàbrica, sinó que la reeixida extensió d'una cultura de protesta — un món bastit de solidaritat — va fer que el seu desenvolupament fonamental es desplacés cap als barris i cap al cen-

106 Entrevista a Teresa Fortuny Solà, Banc Audiovisual de Testimonis, cinta 707, Memorial Democràtic.

107 BARDAJí 2015, 90-95.

108 DUCH \& CAROT 2012, 238.

109 «Joven madre e hijo (dos años) arrollados y muertos por un turismo», Diario Español, 28 oct. 1973; «Manifestación de vecinos de la Floresta», Diario Español, 5 des. 1973. Vegeu la carta del sacerdot Francesc Xammar, membre de l'Assemblea de Tarragona i activista del moviment veïnal, al governador civil Pascual Aige (1o febrer 1974), dins Fons Federació d'Associacions de Veïns de Tarragona (FAVT), Associació de Veïns de la Floresta, c. 5, cp. 3, AHPT. 
tre de la ciutat. ${ }^{110}$ El jovent no tan sols fou partícip en aquells moviments socials, sinó que en va ser un dels engranatges primordials.

El més interessant de les vagues d'aquell període és, d'una banda, el grau d'organització obrera i, de l'altra, la dimensió popular que cobraven els conflictes. La JCC va tenir un paper desdibuixat en la vaga de Valmeline - perquè en aquest cas havien estat les joves a través de $\mathrm{CCOO}$ però la seva dimensió popular i ciutadana és difícilment explicable sense l'impuls donat per la JCC. ${ }^{111}$ D'aquella JC petita i reclosa en espais perifèrics al final dels anys seixanta es va passar a un moviment juvenil estructurat capaç d'interpellar adults de tota condició, abans de la mort del dictador. Heus ací la funció clau que havia de desenvolupar la JCC en l'antifranquisme, tal com l'havien codificat els comunistes: ser la baula que convertís la vaga general en vaga nacional o, tal com fou denominada a partir del 1974, en Acció Democràtica Nacional. ${ }^{12}$ El procés d'agregació de conflictes que havia de conduir a la fi de la dictadura va funcionar, sobretot, com a mite, però va ser un mite útil per esperonar una mobilització social imprescindible per fer fracassar els plans reformistes de la dictadura. En aquest sentit, cal consignar l'alt grau de conflictivitat obrera durant els darrers anys del franquisme: entre el 1973 i el 1976, Espanya, un país on la vaga estava conceptuada com a delicte polític, ocupava els primers llocs europeus en nombre d'hores perdudes, segons dades de l'OCDE. I entre el 1974 i el 1976, els salaris van créixer tres cops més que la productivitat, cosa que retallava els marges de benefici empresarial. ${ }^{113} \mathrm{El}$ fet més remarcable era el canvi qualitatiu que les mateixes autoritats hi observaven. Era evident la dimensió política dels conflictes i l'efecte que això tenia en un moment de crisi institucional. D'altra banda, la seva inserció en el context d'una inflació galopant deixava caducs els convenis collectius, fet que va ocasionar un increment inèdit de la conflictivitat du-

110 Vegeu el pamflet que van editar les CCOO tarragonines: «La huelga de Valmeline (información y valoración)», [set.] 1974, PSUC, uc. 1538, c. 127, ANC. Sobre el conflicte de Valmeline, vegeu DUCH \& FERRÉ 2009, 167-174; CUADRADA \& GUTIÉRREZ 2014, 241-247.

111 «Algunas conclusiones: por un movimiento obrero juvenil», Demà 12 (nov. 1974). Número especial dedicat al moviment obrer tarragoní.

112 Sobre l'Acció Democràtica Nacional, vegeu Treglia 2012, 311 i s.

113 Balfour 1994, 235. 
rant el 1974, que encara havia d'augmentar els anys següents. ${ }^{114}$ Les dades sobre Tarragona resulten eloqüents en aquest sentit: les hores perdudes en l'àmbit provincial van passar de $19.488 \mathrm{el} 1974$ a 1.331.410 el 1976. ${ }^{115}$

La clau de tot plegat era que els moviments com l'obrer - la punta de llança de l'antifranquisme - o el veïnal — principal element de nucleació de les heterogènies classes socials que el formaven i, tanmateix, l'articulador d'alternatives concretes en la quotidianitat- descansaven en el dens entramat social que l'antifranquisme havia contribuït a ordir. Així, doncs, en la societat civil, lentament reconstruïda, era on es produïa el procés metabòlic de totes les alternatives que duien els nous moviments socials i des de la qual aquestes podien disputar el poder al franquisme. Un franquisme progressivament reclòs a posicions defensives, mancat d'iniciativa política, incapaç de canalitzar les demandes creixents que emanaven de la societat. ${ }^{116}$ Heus ací una de les principals contribucions de la JCC a l'antifranquisme: haver contribuit a reconstruir la societat civil i haver-hi pres posicions. Lluny de tota èpica, aquesta labor era la que els seus militants desenvolupaven en els clubs i les associacions juvenils i imprimien aspiracions democràtiques i revolucionàries a la resta de joves. En aquest sentit, seria interessant obrir el debat sobre el rol del jovent comunista com a mediador evanescent $t^{117}$ en la societat civil, i el paper d'aquest en la seva (re)construcció reeixida a mitjan dècada dels anys setanta.

Aquesta mediació evanescent dels joves comunistes pot veure's en un cas com el de Montblanc. Després de la gran participació popular en la primera edició, l'Acampada de la Joventut es va tornar a celebrar el 1975. L’afluència va ser força elevada, i el contingut, més polític. Amb l'aparença d'una conferència sobre la problemàtica agrària a Catalunya, es va poder fer una presentació pública del nou sindicat unitari del camp: Unió

114 Molinero \& YSÀs 1998, 222-223.

115 HeRAS 1991, 288-289.

116 Cfr. DOMÈNECH 2012, 200-209.

117 El terme fou originàriament encunyat per Fredric Jameson per explicar la funció dels jacobins en la construcció de l'estat burgès. Darrerament ha estat emprat per descriure la labor dels comunistes com a agents radicalitzants o mediadors que es fonen en els moviments en què participen -i desapareixen en la seva pròpia intervenció-, cosa que sol coincidir amb l'èxit dels posicionaments sostinguts pels comunistes. Cfr. BALIBAR 2013, 33-35. 
de Pagesos (UP). Si bé l'anterior edició no va tenir conseqüències per als organitzadors, la del 1975 va comportar un enfrontament amb les autoritats eclesiàstiques de la capital de la Conca de Barberà. Sota pretextos morals, tres militants de la JCC van ser expulsats de l'institut que depenia de la diòcesi, i a un grapat de joves més, que procedien de poblacions veïnes, se'ls va fer fora del seminari. L'absurditat de tot plegat fou que un dels denunciants era membre de l'Assemblea de Montblanc. Es tractava d'una persona d'ordre que participava en la gran conspiració per ideals catalanistes i que es degué sentir aclaparat davant la nodrida presència comunista en l'Assemblea, que ell sí que coneixia. Finalment, l'assumpte es va aconseguir solucionar gràcies a la mediació amb l'Arquebisbat d’Antoni Andreu, una figura de pes en l'antifranquisme blanc i que gaudia d'influència entre les classes dirigents. ${ }^{118}$

Les experiències com les de Montblanc, a pesar de la repressió, i la potencialitat dels actes oberts i de massa van convèncer els joves comunistes de la necessitat d'anar més enllà de les coordinadores locals d'entitats que s'havien multiplicat des del 1972. Així, doncs, al final del 1975 es van reunir representants d'entitats juvenils al Centre Bràvium de Reus i van assistir-hi centres de la Pobla de Mafumet, Vilallonga, Vilaplana, l'Alforja, la Selva del Camp, la Canonja i el Club de Joves de Tarragona. De manera parallela, es van reunir a Torredembarra joves d'aquella població i també de les barriades tarragonines de Torreforta, Bonavista i de la ciutat. La convocatòria, per separat, corresponia a motius de seguretat, però els objectius que ambdues s'havien establert eren els mateixos: fer una crida per formar una coordinadora intercomarcal de grups juvenils. ${ }^{119} \mathrm{~A}$ la crida van respondre-hi associacions juvenils de Tarragona, Reus, Alcover, Torredembarra, l'Alforja, Picamoixons, Valls, la Canonja, la Selva i Altafulla, entre d'altres. En aquelles poblacions els clubs de joves no tan sols eren la base del moviment juvenil, sinó la de l'antifranquisme. En moltes localitats tenia presència la JCC, però no en totes. Aquesta era una novetat important: l'antifranquisme no atenyia ja només els sectors organitzats, sinó que apellava la societat civil tenaçment reconstruïda al llarg

118 Entrevista a Andreu Mayayo i Artal, 6 setembre 2016.

119 HERAS 1991, 133.

FRANQUISME \& TRANSICIÓ 4 (2016) ISSN 2014-511X PUNCTUM, UNIVERSITAT OBERTA DE CATALUNYA \& FUNDACIÓ CARLES PII SUNYER 
dels darrers anys. Aquells centres juvenils, si bé encara no tots, havien estat els nuclis impulsors d'assemblees democràtiques i d'associacions de veïns o, en qualsevol cas, havien esdevingut òrgans propulsors de reivindicacions cíviques, socials, laborals i, fins i tot, polítiques. ${ }^{120}$

Aquests joves es veien ells mateixos com a «motors innovadors de la vida rural», com la guerrilla cultural que dinamitaria els ciments del consentiment sobre els quals se sustentava el franquisme: «ho han fet introduint nous corrents culturals, bombardejant els pobles d'una informació que no passi necessàriament pels canals oficials i fent de contrapès, com una nova força, a la pressió que les oligarquies locals exerceixen sobre les voluntats de la gent». ${ }^{11} \mathrm{Amb}$ aquest esperit es van reunir l'11 de gener de 1976 uns cent cinquanta joves a Alcover, en representació de divuit entitats juvenils, i van constituir la Coordinadora de Clubs de Joves del Camp de Tarragona. Un mes després hi aglutinà un total de vint-itres entitats. Com de costum, no es plantejaven finalitats pròpiament polítiques o ideològiques, sinó culturals i de cooperació intercomarcal; al cap i a la fi, la intencionalitat era fer política a través d'aquestes estructures. Amb tot, no feia falta dir que es tractava d'una plataforma impulsada per la JCC i destinada a l'agitació política fins que aquesta no fos legalitzada. Pel que fa a organització, la Coordinadora es va subdividir en tres coordinadores comarcals: Tarragonès, Baix Camp i Alt Camp. La seva funció era doble: dur a terme tasques de coordinació de les accions ja endegades i impulsar noves campanyes i accions capaces de seguir ampliant el moviment. ${ }^{122}$ L'antifranquisme era fonamentalment un moviment d'àmbit local, tot i la seva voluntat supramunicipal. Per exemple, la Coordinadora va impulsar la creació de manifestos juvenils d’àmbit local i comarcal en què es fes esment de situacions particulars de cada cas. Disposem d'una publicació que un grup de joves demòcrates del Baix Camp va publicar amb l'eloqüent capçalera Aurora. ${ }^{123}$

120 Joan Cavallé, «Experiències del moviment de joves al Camp de Tarragona», s.d. [oct.-des. 1976], Fons Iniciativa per Catalunya Verds (ICV), c. 8, AHCT.

121 Ibídem.

122 «Coordinadoras y protagonismo juvenil», Demà 17 (maig 1976).

123 L'Aurora era un vaixell de guerra rus que va participar en la Revolució Russa el febrer del 1917. És considerat el símbol que va donar inici a la Revolució d’Octubre, quan es va negar a salpar i un tret FRANQUISME \& TRANSICIÓ 4 (2016) ISSN 2014-511X PUNCTUM, UNIVERSITAT OBERTA DE CATALUNYA \& FUNDACIÓ CARLES PII SUNYER 
Al final del 1975, l'Assemblea de Catalunya va revifar al Baix Camp i es va estendre a l'Alt Camp i a la Conca de Barberà. Aquest impuls va arribar gràcies a la JCC, a través de la força que feien les coordinadores locals i comarcals. A Tarragona, d'altra banda, van augmentar els grups polítics adherits a l'Assemblea. El març de 1976, l'Assemblea de Tarragona disposava de la presència d'independents, CCOO, PSUC, FNC, PSAN, la nova Convergència Socialista de Catalunya (CSC), que substituïa l'MSC, el Moviment Comunista (MC), el Partit Carlí i el nou Partit del Treball d'Espanya (PTE), denominació que va prendre el PCE(i) a partir del febrer del 1975. El gener del 1976, l'Assemblea va convocar una manifestació per demanar la llibertat de Josep M. Yago, militant del PSUC empresonat a Tarragona, i va esperonar les manifestacions per l'amnistia celebrades a Valls, que foren prèvies a les del febrer a Barcelona. ${ }^{124}$

L'hegemonia antifranquista es feia patent i la crisi del règim n'havia esmicolat el grup dirigent. El 25 de març de 1976, el regidor municipal Agustí Rosell Saurina va posar a votació del ple un text perquè l'ajuntament de Tarragona s'adherís als punts de l'Assemblea de Catalunya, un document que portava la signatura d'uns altres dos regidors franquistes. L'ajuntament va aprovar el text, però fou suspès pel Govern Civil i es va obligar el ple a aprovar-ne un altre que contradeia el primer. ${ }^{125}$ La socialització antifranquista arribava cada cop a sectors més amplis de la societat civil i les manifestacions en contra del règim es multiplicaven. Per exemple, dos joves que no arribaven a quinze anys van ser detinguts a la petita població de Caseres (Terra Alta) «por haber pintado frases subversivas en las pizarras, paredes, y sobre dos carteles con los textos del testamento político de Franco y del discurso de coronación del Rey». ${ }^{126} \mathrm{Du}$ rant les protestes de rebuig pels fets del 3 de març a Vitòria va morir el jove treballador Juan Gabriel Rodrigo Knafo quan fugia de la policia a

\footnotetext{
de canó va ser el senyal perquè els bolxevics assaltessin el Palau d'Hivern. Vegeu les demandes dels joves del Baix Camp (amb tota seguretat, de la JCC) a «Manifest», Aurora: Portaveu dels joves demòcrates del Baix Camp 1 (s.a. [1976]). Es conserva al Fons Jóvenes en Libertad, AHT.

124 MAYAYO 2002, 21-22.

125 Heras 1991, 160.

126 «Caseras (Tarragona): dos estudiantes detenidos por la Guardia Civil», 24 abril 1976, Cultura, c. 42/9112, AGA.
} 
Tarragona. ${ }^{127}$ La repressió policial que li va costar la vida a Rodrigo Knafo va provocar grans manifestacions a Tarragona i va deixar veure les desavinences que hi havia entre els grups antifranquistes sobre l'actitud que calia dispensar a les forces de l'ordre. ${ }^{128}$ Pel que fa als franquistes, es trobaven cada cop més reclosos, i, incapacitats per canalitzar la situació, la majoria d'ells es van refugiar en la tothora present repressió. En aquell moment van proliferar accions de collectius, especialment de composició juvenil, d'extrema dreta (com la denominada Asociación Democrática de Trabajadores i el Comando Negro de Falange). L'episodi més sonat d'aquests grups va ser l'intent d'incendiar l'edifici del Govern Civil de Tarragona, si bé la seva actuació habitual era amenaçar de mort els líders obrers i imprimir propaganda falsa en nom de CCOO i de grups comunistes. Tot i que se seguia castigant severament la participació popular en manifestacions contra el règim, amb la mort de Franco la paranoia es va apoderar de la ment de moltes persones. N'és bon exemple un funcionari de Correus de Cambrils que va ser expedientat per no haver dut corbata negra l'endemà del traspàs del Generalísimo. ${ }^{129}$

L'11 de desembre de 1975, la CONC va convocar una vaga general de vint-i-quatre hores a Catalunya per reivindicar la descongelació salarial que el govern d'Arias Navarro havia establert, i per l'amnistia i les llibertats sindicals i polítiques «en el camino de la HUELGA GENERAL Y DE LA ACCIÓN DEMOCRÁTICA NACIONAL que liquiden a la dictadura e impongan la libertad y la democracia».130 L'Assemblea de Tarragona va secundar la crida i la Coordinadora d'Estudiants va esperonar la mobilització general en contra de la continuïtat joancarlista. El seguiment de la vaga va ser modest en l'àmbit laboral, però elevat en l'estudiantil. L'institut Martí i Franquès va tancar les portes i l'activitat a la delegació universitària va ser pràcticament nulla. La policia va fer algunes detencions, com les de

127 «Una persona resultó gravísimamente herida en los incidentes ocurridos esta tarde en Tarragona», 5 març 1976; "Grave enfrentamiento manifestantes policía», 5 març 1976, ambdós a Cultura, c. 42/9112, AGA.

128 Entrevista a Josep Sánchez Cervelló, 20 juny 2016.

129 Heras 1991, 194.

130 «Trabajadores, pueblo de Tarragona», crida de CCOO de Tarragona, 1 desembre 1975, recollit a HERAS 1991, 146. 
Xavier Arnau i d'Enric Gibert, membres de la JGR, però en general no van aconseguir que Tarragona recuperés la normalitat. ${ }^{131}$

Tot i això, el gran resultat de $\mathrm{CCOO}$ en les eleccions sindicals del maig del 1975, la proliferació d'assemblees obreres en els llocs de treball i l'increment de participants en aquelles que s'anaven portant a cap als locals sindicals van suposar un gran salt endavant en el moviment obrer de la ciutat. Per als objectius d'aquest treball, convé remarcar el protagonisme que el jovent va adquirir durant la campanya sindical del 1975. Les seves reivindicacions, que figuraven en llocs destacats entre les demandes generals del moviment obrer i democràtic, en són una bona mostra. ${ }^{132} \mathrm{Du}-$ rant els mesos de gener i febrer es van produir diverses vagues en el sector de la construcció, que, en certa manera, es van convertir en un assaig de vaga general en el terreny local. Tot i que no s'estaven negociant els convenis collectius, CCOO va creure convenient coordinar una acció a Tarragona amb les vagues que es desenvolupaven al Baix Llobregat i pretenia aconseguir mobilitzar el ram de la construcció per demandes salarials. Al gener van aturar l'activitat algunes empreses i aviat la vaga, que es va allargar dotze dies, va afectar seixanta-set empreses i més de 3.500 treballadors. Després d'una anormal tornada a la feina, al febrer es va reprendre la vaga i es va estendre pel Camp de Tarragona (va arribar a implicar-hi uns 6.000 treballadors). ${ }^{133}$

Atesa la creixent integració entre moviment obrer, societat civil i antifranquisme polític, l'activitat laboral a la ciutat es va notar en altres sectors, a part del de la construcció. Molts comerciants van tancar les botigues, i les manifestacions contra el règim i per l'amnistia es van multiplicar durant el període de vaga. La JCC va realitzar diverses accions per reivindicar l'amnistia. Van collocar una pancarta en què s'exigia la democràcia i la llibertat i van convèncer els bombers que havien acudit a retirar-la perquè la deixessin. En efecte, la demanda d'amnistia política era la que tenia més capacitat d'aglutinar la societat civil. Durant aquells dies, una vintena de joves comunistes van començar a fer segudes diària-

131 «Detenidos presuntos miembros organización ilegal», 11 desembre 1975, Cultura, c. 42/9112, AGA.

132 Cfr. «A la clase obrera», CL de Tarragona del PSUC, maig de 1975, PSUC, uc. 940, c. 54, ANC.

133 Mota MuÑoz 2010, 90 i 103.

FRANQUISME \& TRANSICIÓ 4 (2016) ISSN 2014-511X PUNCTUM, UNIVERSITAT OBERTA DE CATALUNYA \& FUNDACIÓ CARLES PII SUNYER 
ment davant la presó provincial per demanar l'amnistia dels presos polítics. ${ }^{134}$ El grau de conflictivitat social i de crisi institucional era tal que els empresaris van deixar d'utilitzar els canals de negociació previstos per la legislació i negociaven directament amb CCOO. El dirigent local de CCOO José Estrada va ser detingut mentre participava en un piquet que va enfrontar-se a la policia durant la vaga de la construcció. ${ }^{135}$ Un cop a la presó, va rebre la visita del dirigent de la patronal tarragonina de la construcció per tal d'arribar a un acord que posés fi al conflicte. Estrada va escriure, llavors, una carta des del presidi en què instava a reincorporar-se a la feina després d'haver aconseguit el que estimava com un bon tracte amb la patronal. Aquest, però, fou incomplert sistemàticament pels empresaris, cosa que va motivar que se seguissin fent assemblees i que algunes empreses decidissin prosseguir la vaga. ${ }^{136}$

La conflictivitat social, amb tot, no se circumscrivia tan sols al moviment obrer, a les barriades o als estudiants, sinó que arribava a sectors que fins aleshores havien estat incapaços de fer demostracions públiques d'envergadura. A inicis del 1976, la majoria de pagesos i ramaders estaven subjectes a un conveni collectiu del camp ja caduc. S'esperava que el govern decretés la regulació de preus de campanya per a diversos productes agraris que permetés que molts pagesos arribessin a uns preus mínims que els garantissin poder seguir vivint de la terra. En les multitudinàries assemblees celebrades durant els primers mesos de l'any a la Cambra Oficial Sindical Agrària (COSA), les autoritats del vertical afirmaven públicament l'acord amb les demandes pageses, però, en la pràctica, no movien els fils pertinents per solucionar la situació. ${ }^{137} \mathrm{El}$ jovent se sentia interpellat per la situació dels pagesos, ja que molts d'ells eren pares i fills. En una de les assemblees es van escapolir un grapat d'estudiants de la Laboral per intentar truncar el funcionament normal del sindicat vertical del camp i els verticalistes els feren fora. Finalment, el descontentament latent de la pagesia es va fer evident quan van ser de-

134 «Des del pasado martes, 20 jóvenes efectúan diariamente una sentada frente a la prisión provincial, en petición de amnistía», 23 gener 1976, Cultura, c. 42/9112, AGA.

135 Entrevista a José Estrada Cruz, 7 febrer 2008, FS, AHCT.

136 Heras 1991, 146-148.

137 Assemblea General de la COSA, 9 abril 1976, Fons COSA, c. 58, p. 51b-52, AHPT.

FRANQUISME \& TRANSICIÓ 4 (2016) ISSN 2014-511X PUNCTUM, UNIVERSITAT OBERTA DE CATALUNYA \& FUNDACIÓ CARLES PII SUNYER 
tinguts a les Borges Blanques tres sindicalistes de la UP mentre collocaven una pancarta en què es demanaven preus remuneradors per a l'oli. Així, els membres de l'oposició van aconseguir aglutinar la majoria en l'assemblea de la COSA i van convocar una manifestació a Tarragona per a l'11 de maig. L'afluència popular a la protesta va ser impressionant. Deu mil pagesos - la meitat, segons dades governamentals - es van desplaçar a Tarragona per a l'ocasió. Sota el lema «Volem viure de la terra», van caminar per la Rambla Nova sense intervenció de la policia, que, d'altra banda, envoltava l'edifici del Govern Civil com a mesura de prevenció. Els joves universitaris van desplegar una gran pancarta on es llegia «La Universitat amb el Pagesos».138

La JCC de les zones rurals tenia la consigna d'entrar a la UP des que es va constituir, el novembre del 1974. Durant la II Conferència Nacional, el nou secretari general de la JCC, Josep Maria Riera, va esperonar els joves pagesos a revitalitzar la UP per evitar que es reproduís una situació com la d'anys enrere amb les CCPP. Tot i no arribar al miler de pagesos joves a tot Catalunya, Riera esperava que la UP pogués assumir els plantejaments de defensa de la joventut a les poblacions rurals. ${ }^{139} \mathrm{Amb}$ tot, el pes dels pagesos en la JCC era modest. A principis del 1976, tant el partit com la joventut van dur a terme canvis organitzatius d'una certa importància. La intercomarcal del PSUC va nomenar Matíes Vives el seu responsable i es va ampliar la presència del partit a noves poblacions, com també de la JCC al Priorat. L'organització local de Tarragona del PSUC va viure un gran salt de militància en aquells moments, ja que entre el novembre del 1975 i el maig del 1976 gairebé va doblar-ne els membres.

El febrer del 1976 es va celebrar el I Ple Ampliat del Comitè Intercomarcal del Camp de Tarragona de la JCC en una masia de l'Aleixar. Una ullada a la composició dels seus delegats ens ajudarà a copsar millor quina era la base des de la qual l'organització podia incidir en la societat i contribuir a construir aquella JCC, que es volia de masses. El segment més gran de militants corresponia a joves obrers (35\%), mentre que el

138 Ferrer GoNZÁLEZ 2014, 93-96.

139 «Hacia la unidad de los movimientos juveniles», informe del CE en la II Conferència Nacional de la JCC presentat per Josep M. Riera, 3 oct. 1976, PSUC, uc. 1271 (III), c. 75, p. 18, ANC. 
més petit incloïa pagesos ( $5 \%$ ). Un fet prou significatiu era la nodrida presència d'estudiants (30\%), així com d'estudiants que també treballaven (representaven el $30 \%$ de l'organització). ${ }^{140} \mathrm{El}$ Ple va organitzar les celebracions públiques amb motiu del sisè aniversari de l'organització juvenil per al mes de juliol, coincidents amb les festes dels quaranta anys del PSUC. A més, s'hi introduïen canvis derivats de la sortida a la superfície que la direcció del PSUC propugnava. El més significatiu va ser el de donar per acabada l'etapa de Demà com a portaveu intercomarcal i començar a publicar Joventut, el primer número del qual va sortir el novembre del $1976 .{ }^{141}$

La novetat de Joventut respecte a Demà va ser que els articles van començar a estar signats, i no precisament amb pseudònims. La sortida a la superfície exigia moviments audaços, com ara mostrar-se a la llum pública, i els seus quadres dirigents havien de ser els primers de fer-ho. ${ }^{142} \mathrm{El}$ contingut temàtic a Joventut també va mostrar canvis evidents, que posaven de manifest la voluntat de la JCC d'esdevenir una organització de masses — una «organització nova» a l'estil togliattà — arrelada entre la gent, amb capacitat per seguir ordint un dens entramat social i avançar cap al socialisme; amb capacitat per ordenar i donar resposta a totes les qüestions de la vida i erigir-se com a institució de lluita, certament, però també, a través de l'establiment de normes implícites i explícites, com a reguladora de la quotidianitat. Una organització que, seguint la comunista italiana Rossana Rossanda, aspirés a forjar una xarxa (densa, però viva) que estructurés un poble d'esquerres contra les opinions imposades des dels canals de l'oficialitat; que construís institució popular, i que fos capaç d'articular una visió global del món a través del prisma comunista que representés, alhora, el poble en conjunt i no només una part. ${ }^{143}$

Y si hoy nos planteamos el avanzar decididamente hacia esta organización nueva es porque tenemos las bases para hacerlo, bases que se han ido cons-

140 Heras 1991, 131.

141 Poden consultar-se els quatre números de Joventut (novembre de 1976 - agost de 1977) al fons ICV, c. 14, AHCT.

142 Entrevista a Andreu Mayayo i Artal, 6 setembre 2016.

143 Rossanda 2005, 117-118. 
truyendo a lo largo de todos estos años de una JCC que ha estado presente y ha contribuido al desarrollo del movimiento juvenil en Catalunya. No partimos de cero, sino que partimos de una JCC que nos permite dar este salto a todos los niveles que hemos hoy de hacer. ${ }^{144}$

Si bé no s'expressaren en aquests termes que empraria Rossanda en les seves memòries, sí que era un debat de fons en la II Conferència Nacional de la JCC. Eren unes fites que, tot i que encara no s'havien aconseguit desenvolupar, havien sembrat la llavor perquè florís aquella organització nova que es considerava revolucionària i capaç de capgirar els valors del passat i construir persones noves, més lliures i iguals. Davant el referèndum sobre la Llei de reforma política, al qual l'antifranquisme s'oposà si no es garantien prèviament els drets democràtics, ${ }^{145}$ la JCC seguia amb la voluntat de formar una institució popular que, eventualment, estigués en disposició d'articular no tan sols una alternativa de govern, sinó de sistema. Les bases per a la construcció d'una organització de masses que s'enfrontés no només al franquisme, sinó que tingués la capacitat de fer un poble nou després de la dictadura, havien quedat establertes. Finalment, fou un somni frustrat. Amb tot, durant el franquisme, la JCC va ser capaç de posar els seus fonaments, també més enllà de la Gran Barcelona. Un prerequisit per comprendre què va passar després.

\section{Bibliografia}

Acil, Rafael, Andreu Mayayo i Antoni Segura, ed. 2003. Memòria de la transició a Espanya i a Catalunya. Els joves de la transició, 4 vol. Barcelona: Edicions UB.

Alonso, V.L. et al. 1976. Crisis agrarias y luchas campesinas, 1970-1976. Madrid: Ayuso.

BABIANO, José. 1995. Emigrantes, cronómetros y huelgas. Un estudio sobre el trabajo y los trabajadores durante el franquismo (Madrid, 1951-1977). Madrid: Siglo XXI.

BALFOUR, Sebastian. 1994. La dictadura, los trabajadores y la ciudad. El movimiento obrero en el área metropolitana de Barcelona (1939-1988). València: Ed. Alfons el Magnànim.

144 «Hacia la unidad de los movimientos juveniles», informe del CE a la II Conferència Nacional de la JCC presentat per Josep M. Riera, 3 octubre 1976, PSUC, uc. 1271 (III), c. 75, p. 25, ANC.

145 «No voteu», CL de Tarragona del PSUC, s.d. [des. 1976], PSUC, uc. 940, c. 54, ANC. 
BALIBAR, Étienne. 2013. «Communism as Commitment. Imagination, and Politics». Dins Slavoj ZızeK, ed., The Idea of Communism, 2 vol. Londres/Nova York: Verso. BARDAJí, Federico. 2015. Bonavista, una biografía social. Tarragona: Silva.

CASAdo Gómez, Carlos Alejo. 2007. «De la Unión de Juventudes Comunistas a la Juventud Socialista Unificada». Dins Manuel Bueno, José Hinojosa i Carmen GARCía, coord., Historia del PCE. I Congreso, 1920-1977, 1 vol. Madrid: Fundación de Investigaciones Marxistas.

Caussa, Martí, i Ricard Martínez i Muntada, ed. 2014. Historia de la Liga Comunista Revolucionaria (1970-1991). Madrid: La Oveja Roja.

Colomer, Josep M. 1978. Els estudiants de Barcelona sota el franquisme, 2 vol. Barcelona: Curial.

CuAdrada, Coral, i Esther GutiérRez, ed. 2014. Les dones en els orígens de Torreforta. Tarragona: Universitat Rovira i Virgili / Cercle d'Estudis Històrics i Socials Guillem Oliver del Camp de Tarragona.

Domènech, Xavier. 2008. Temps d'interseccions. La Joventut Comunista de Catalunya (1970-1980). Barcelona: Fundació Francesc Ferrer i Guàrdia.

- 2012. Cambio político y movimiento obrero bajo el franquismo. Lucha de clases, dictadura y democracia (1939-1977). Barcelona: Icaria.

DuCH, Montserrat, i Tomàs CAROT. 2012. Història de Tarragona. República, dictadura $i$ democràcia. Lleida: Pagès.

Duch, Montserrat, i Meritxell Ferré. 2009. De súbdites a ciutadanes. Dones a Tarragona, 1939-1982. Tarragona: Universitat Rovira i Virgili / Cercle d'Estudis Històrics i Socials Guillem Oliver del Camp de Tarragona.

EscodA, Jordi. 2007. Memòria històrica d'un reusenc. La Transició. Valls: Cossetània.

FERNÁNDEZ SORIA, Juan Manuel. 1992. Juventud, ideología y educación. El campromiso educativo de las Juventudes Socialistas Unificadas. València: Publicacions de la Universitat de València.

FERRER GONZÁlez, Cristian. 2014. Lluitadors quotidians. L'antifranquisme, el canvi polític i la construcció de la democràcia al Montsià (1972-1979). Lleida: Universitat de Lleida.

- 2016. «Resistencias y desafíos al franquismo. Las Comisiones de Campesinos y Jornaleros del Campo Catalán». Comunicació presentada en Old and New Worlds: the Global Challenges of Rural History, International Conference, Lisboa, 27-30 de gener de 2016. https://lisbon2016rh.files.wordpress.com/2015/12/o032-onw1.pdf.

GALLEGo, Gregori. 1996. Els anònims de la transició. Història del moviment obrer a Lleida i a Balaguer (1960-1970). Lleida: Pagès.

Heras, Pedro A. 1991. La oposición al franquismo en las comarcas de Tarragona (19391977). Tarragona: Mèdol.

Her BERA, Albert. 2006. «J. M. Céspedes i la Joventut Comunista de Catalunya (19761982)». Dins Celestino SÁNCHEz et al., Jotaeme: la joventut del comunisme. Barcelona: Fundació Pere Ardiaca.

Llop Tous, Josep. 2002. La industrialització de Tarragona (1957-1971) i les seves circumstàncies. Tarragona: Arola. 
MARgalef, Joaquim. 1979. El Tarragonès. Estructura econòmica, expansió industrial i desequilibris sectorials. Barcelona: Caixa d'Estalvis de Catalunya.

MARRUGAT, Ramon. 2012. La Llibreria de la Rambla i l'alternativa cultural de Tarragona (1968-1980). Tarragona: Cercle d'Estudis Històrics i Socials Guillem Oliver del Camp de Tarragona.

Martín Ramos, José Luis, coord. 2011. Pan, trabajo y libertad. Historia del Partido del Trabajo de España. Mataró: El Viejo Topo.

MAYAYO, Andreu. 2002. La ruptura catalana. Les eleccions del 15-J de 1977. Barcelona: Afers.

Molinero, Carme. 1997. «Recuperació econòmica i canvi social». Dins Borja de RIQuer, dir., Història, política, societat i cultura als Països Catalans. La llarga postguerra, 1939-1960, 10 vol. Barcelona: Enciclopèdia Catalana.

Molinero, Carme, i Pere Ysàs. 1998. Productores disciplinados y minorías subversivas: clase obrera y conflictividad laboral en la España franquista. Madrid: Siglo XXI.

- 2010. Els anys del PSUC. El partit de l'antifranquisme (1956-1981). Barcelona: L'Avenç.

Mota MuÑOz, José Fernando. 2010. «Mis manos, mi capital». Els treballadors de la construcció, les CCOO i l’organització de la protesta a la Gran Barcelona (1964-1978). Barcelona: Germania.

PALA, Giaime. 2011. El PSUC. L'antifranquisme i la política d'aliances a Catalunya (19561977). Barcelona: Base.

- 2016. Cultura clandestina. Los intelectuales del PSUC bajo el franquismo. Granada: Comares.

Rossanda, Rossana. 2005. La ragazza del secolo scorso. Torí: Einaudi.

Rovira I Gómez, Joan-Salvador. 2010. El Club de Joves (1965-1976). El ressorgiment de la cultura catalana i catalanista a Tarragona. Tarragona: Universitat Rovira i Virgili / Cercle d'Estudis Històrics i Socials Guillem Oliver del Camp de Tarragona.

Souto Kustrín, Sandra. 2016. «Las organizaciones juveniles de la República frentepopulista: entre el rechazo total y la adhesión incondicional». Nuestra Historia 1: 82-99.

Treglia, Emanuele. 2012. Fuera de las catacumbas. La política del PCE y el movimiento obrero. Madrid: Enaida.

VIÑAS, Ricard. 1978. La formación de las Juventudes Socialistas Unificadas (1934-1936). Madrid: Siglo XXI. 